\title{
Customer Relationship and Sales
}

\author{
Shouyong Shi* \\ Department of Economics \\ University of Toronto \\ (shouyong@chass.utoronto.ca)
}

This version: September 2012

\begin{abstract}
I analyze a search equilibrium of a large market where customer relationship arises endogenously together with service priority and sales. A buyer is related to a seller if he just purchased from the seller, and the relationship is broken if the buyer fails to buy from the seller. I prove that there exists a unique equilibrium where it is optimal for a buyer to make repeat purchases from the related seller and optimal for a seller to give service priority to the related buyer. Moreover, a related seller posts a (high) regular price, and an unrelated seller posts a (low) sale price with the intention to revert to the regular price once he gains a relationship. The fraction of related sellers is endogenous. I examine how market conditions affect the stock of relationships, markups, the size and the duration of a sale.
\end{abstract}

JEL classifications: D83; D40.

Keywords: Customer relationship; Sales; Directed search.

* Address: 150 St. George Street, Toronto, Ontario, Canada, M5S 3G7. A version of this paper has been presented at the Econometric Society Winter meeting (Chicago, 2012), the Tokyo Conference of the OEIO (Tokyo, 2012), Boston University (2012), and the NBER Summer Institute (2012). I thank the participants of those conferences and seminars for comments. I also thank Oleksiy Kryvtsov for insightful conversations on the topic. Financial support from the Canada Research Chair, the Bank of Canada Fellowship, and the Social Sciences and Humanities Research Council of Canada is gratefully acknowledged. The opinion expressed here is my own and does not reflect the view of the Bank of Canada. 


\section{Introduction}

Sellers often give service priority to repeat buyers. For example, a restaurant may give the reservation priority to patrons, and an airline company may allow frequent flyers to select seats in advance and board earlier. Such customer relationship is often informal, and neither side of the relationship is abided by any agreement to continue the trade in the future. Although common in practice, customer relationship has not been formally modeled as an endogenous outcome of an equilibrium. In this paper, I demonstrate that customer relationship arises in the equilibrium of a large market with search frictions and implies a seller's optimal pricing strategy that involves sales. I analyze how market conditions affect the stock of relationships, markups, the size and the duration of a sale.

A formal model of customer relationship in a large market is useful for the following reasons. First, repeat purchases are prevalent in retail transactions. Although the marketing literature has emphasized customer loyalty, it has taken customer loyalty as a primitive of the model (e.g., Blattberg and Sen, 1974). Endogenizing customer relationship as an equilibrium outcome in a large market helps understanding why it is prevalent. Second, a theory of customer relationship can help explaining some salient features of price dynamics at the micro level of retailers. In particular, prices exhibit large variability over time for the same item at a given store, sales account for a significant part of this variability, and prices excluding sales are sticky. ${ }^{1}$ When competition for repeat purchases is important, it is natural that a seller may hold sales from time to time to attract buyers. Once a relationship is formed, a seller may keep price relatively stable while using non-price instruments, such as service priority, to maintain the relationship.

To be concrete, I study a market with a large number of buyers and sellers, where a seller in each period tries to sell one indivisible unit of a homogeneous good and buyers have the same publicly known valuation of the good. In each period, buyers observe the terms of trade offered by sellers before choosing which seller to visit. As is standard in the search literature, search frictions are such that individuals cannot coordinate their

\footnotetext{
${ }^{1}$ See Klenow and Kryvtsov (2008) and Nakamura and Steinsson (2008).
} 
decisions and that buyers cannot switch sellers within one period. With these frictions, a seller may fail to get a visitor in a period and a buyer may fail to be selected by the seller he visits. Hence, there is a tradeoff between the price of the good and the probability of trade. Sellers and buyers may want to form relationships in order to increase the probability of trade. Consider the possibility that a seller treats a buyer who bought from him in the previous period as the related buyer and rewards the buyer with the priority of trade over unrelated buyers. Since a sale is commonly understood as a price cut available to all buyers, I assume that a seller is not allowed to offer one price to the related buyer and another price to unrelated buyers. ${ }^{2}$ In this model, there is nothing hard-wired about customer loyalty; instead, the two individuals in a relationship can trade with anyone they want to.

I characterize and prove existence of a unique equilibrium in which it is optimal for a seller to give priority to the related buyer and optimal for a buyer to make repeat purchases from the related seller. Like any relationship, the relationship in this model generates benefits to the partners intertemporally and has implications on prices. A relationship enables a buyer to secure trade with the related seller in the future. Knowing this benefit of a relationship to the buyer, the related seller posts a high price that makes the related buyer just slightly prefer visiting him to visiting other sellers. An unrelated seller posts a low price in order to attract buyers and acquire a relationship. In the equilibrium, related buyers only visit their related sellers and unrelated buyers only visit sellers who have no related buyers.

Individual prices follow stylized dynamics in the equilibrium. A seller posts the high price as long as he has a related buyer and, after he loses the relationship, the seller posts the low price until he gains a relationship. Because an unrelated seller cuts the price with the intention to revert to the high price later, the low price can be interpreted as a sale price and the high price as the regular price. A relationship is broken if the buyer fails to

\footnotetext{
${ }^{2}$ This accords with the definition of a sale in the BLS data (see Klenow and Kryvtsov, 2008, and Nakamura and Steinsson, 2008). Thus, this model is not one about price discrimination. The abstraction from price discrimination makes the results more robust. If a seller is allowed to price discriminate, it is easy to generate a differential between the prices posted by a seller for related and unrelated buyers. For such models of in the labor market with wage discrimination, see Shi $(2002,2006)$ and Shimer $(2005)$.
} 
visit the related seller. There is a taste shock that makes a buyer inactive in each period, in which case the relationship is destroyed. At the aggregate level, some unrelated sellers acquire the relationship in each period as they succeed in trade, and some related sellers lose the relationship as they fail to trade. These flows of individuals between the two types endogenously determine the stock of relationships in the market and its dynamics.

The model has precise predictions on the frequency, the duration and the price discount of sales. The extensive and intensive margins of the market affect the equilibrium differently. The extensive margin of the demand has two dimensions: the buyer/seller ratio and the probability that a buyer is active in a period. The intensive margin of the market consists of the utility and the cost of a good. In the steady state, the frequency of sales, the duration of a sale and the fraction of related sellers in the market depend only on the extensive margin and not on the intensive margin of the market. In contrast, prices, markups and sale discounts depend on both margins.

To examine more specifically the effects of market conditions, I compute the steady state. The exercise reveals that customer relationship can induce large variations in retail prices. Specifically, the sale price is a sizable markdown on the marginal cost and the regular price is a significant markup. Relegating the details to section 4, I mention some comparative statics here. First, the regular price is more stable than the sale price in the response to changes in market conditions. Second, the duration of a sale reflects changes in market conditions more accurately than do markups and price discounts of sales. For example, markups and price discounts can respond non-monotonically to an increase in the buyer/seller ratio, but the duration of a sale always decreases in this ratio. Third, an increase in the demand arising from a higher buyer/seller ratio increases the average price of the good, but an increase in the demand arising from a higher probability that a buyer is active in the market can reduce the price.

In this model, search is directed in the sense that buyers know the terms of trade before choosing which seller to visit. This assumption contrasts with the earlier search literature which assumes that buyers do not know the terms of trade until they are matched. Directed 
search is a reasonable assumption. Buyers in many markets have information about the product and the price at particular stores and choose where to shop, rather than randomly search among all sellers. Directed search is a useful modeling device to capture ex ante competition in a market with search frictions. The growing literature on directed search is originated in Peters $(1984,1991)$ and Montgomery (1991). The particular approach in Peters (1991) is used here to derive each individual's trading probability endogenously as a function of strategies, which captures explicitly how a seller's decision on whether to give priority to the related buyer affects the seller's trading probability. ${ }^{3}$

This paper contributes to the literature of directed search in three main aspects. First, this paper focuses on customer relationship which the literature has not studied. Second, customer relationship serves as an endogenous state variable in an individual's decision problem, which induces price dynamics that are absent in the literature of directed search. Third, this paper shows that a seller with a related buyer charges a higher price and is more likely to succeed in trade than a seller without a related buyer, despite that all sellers are identical in exogenous characteristics. This result helps explaining why there has been a lack of strong evidence for the negative relationship between price and the seller's trading probability that is predicted by a canonical model of directed search.

This paper is also related to the literature on sales, which has a few strands. The first strand relies on the result that when each seller faces a discontinuous demand curve, the equilibrium features a mixed strategy in posted prices (Shilony, 1977). Extending this result, some authors interpret price reductions in the mixed strategy as sales, e.g., Salop and Stiglitz (1982) and Varian (1980). ${ }^{4}$ The second strand is based on Sobel (1984), which is modified by Albrecht et al. (2011) to incorporate directed search. In this strand, a constant flow of buyers enter the market in each period who are either high-valuation

\footnotetext{
${ }^{3}$ Other examples of this strategic approach are Julien et al. (2000), Burdett et al. (2001), Albrecht et al. (2006), Galenianos and Kircher (2009), and Kircher (2009). For the alternative approach to directed search that assumes a matching function, see Moen (1997), Acemoglu and Shimer (1999), Shi (2009), Gonzalez and Shi (2010), Guerrieri et al. (2010), and Menzio and Shi (2011). Moreover, some models of directed search in the labor market have incorporated trading priority (e.g., Shi, 2002, 2006, and Shimer, 2005), but they have assumed that the priority comes with explicit price discrimination.

${ }^{4}$ Note that the mixed strategy can be purified when there are a large number of sellers and buyers, as in Burdett and Judd (1983).
} 
buyers local to particular sellers or low-valuation shoppers who can patiently wait for sales. As the stock of patient shoppers reaches a critical level, some sellers cut prices to clear this stock. A sale lasts for one period in this model. ${ }^{5}$ The third strand contains signaling models in which a seller uses promotional sales to signal either the quality of the product (e.g., Milgrom and Roberts, 1986) or the cost of the product (e.g., Bagwell, 1987).

I emphasize customer relationship, instead, although the model also has implications on sales. As a mechanism to generate sales, customer relationship has its intuitive appeal and is complementary to those examined in the literature above. The theory helps explaining the regularity and the duration of sales. Also, it can generate a sale as a markdown, which is consistent with the data (e.g., Dutta et al, 2002) but missing in most of the above literature. Finally, the literature on sales typically models a few sellers and/or buyers, and some of the models are difficult to be made dynamic. In contrast, my model has an infinite horizon and many (in fact, infinitely many) sellers and buyers, which can be useful for analyzing large retail markets. To focus on the link between customer relationship and sales, I deliberately abstract from some elements that are important in the above literature on sales, such as durability of the good, heterogeneity in buyers' preferences, and private information in buyers' valuation or the quality/cost of the product. ${ }^{6}$

\section{A Model of Directed Search with Customer Relationship}

\subsection{The model environment}

Time is discrete and lasts forever. There are $M$ sellers and $N$ buyers, where $M$ and $N$ are large numbers which I will take to the limit $\infty$. Denote $b=N / M$ as the buyer-seller ratio, and fix $b \in(0, \infty)$ until section 5. All individuals discount future at a rate $r>0$. In each period, a seller can produce one indivisible unit of good, at a cost $c \geq 0$. Because goods are perishable, a seller produces a good only after meeting a buyer. In any given period,

\footnotetext{
${ }^{5}$ Related to but different from Sobel's (1984) model, Lazear (1986) assumes that a seller does not know the value of the good to the buyers. After failing to sell the good, a seller updates his beliefs on buyers' valuation downward and reduces the price to clear the inventory of goods.

${ }^{6}$ The model by Gourio and Rudanko (2011) is also broadly related to mine, but they assume that firms' pricing decisions depend exogenously on the customer base.
} 
a buyer has the need to consume a good with probability $\lambda \in(0,1)$. These taste shocks occur at the beginning of the period, which are iid among the buyers and across time. ${ }^{7}$ Call a buyer an active buyer if he has the need to consume, and an inactive buyer if he does not have the need. In each period, the number of active buyers is $\lambda N$. The utility of consumption is $U(>c)$ to an active buyer. I refer to the number of active buyers per seller, $b \lambda$, as the extensive margin of the demand, as opposed to the intensive margin of the market which is determined by $U$ and $c$.

Although all sellers are identical in the production capacity and cost, and all active buyers have the same taste, individuals may have different histories of trade. If a seller sold a good in the previous period to a buyer, the two individuals are related to each other; if a seller did not sell a good in the previous period, the seller is unrelated. For brevity, I refer to this history of trade as an individual's type. A seller's history is publicly observed. The focus is on the equilibria with priority where sellers give priority to their related buyers; that is, if a buyer visits the seller related to him, the seller chooses to trade with the buyer over all other visitors. I will find the condition under which it is optimal for a seller to give such priority.

In each period, sellers simultaneously post the terms of trade. After observing the terms of trade, active buyers choose which seller to visit. After receiving visitors, a seller chooses one visitor to trade with. Sellers must post the terms of trade before knowing which buyer is active in the period, and each buyer must make the visiting decision without knowing other buyers' choices. Moreover, a seller must sell a good for the same price independently of which type of buyers will visit him; that is, a seller is not allowed to use price to discriminate different buyers. As explained in the introduction, this assumption is intended to capture the fact that a sale is available to all buyers and to make the results robust. However, a seller is allowed to give priority to the related buyer, as described above. If all visitors are unrelated to the seller, the seller randomly selects one to trade

\footnotetext{
${ }^{7}$ Alternatively, one can assume that a buyer exits the market with probability $1-\lambda$ in each period and is replaced by a new buyer. The results are similar to the ones here if each seller must post a price without knowing the identities of the buyers who exited.
} 
with. Thus, the posted price can depend on the seller's type.

A relationship between a buyer and a seller is informal. A buyer is free to shop at any seller, and a seller gives priority to the related buyer only when it is optimal to do so. Moreover, a relationship ends when the buyer fails to visit the seller, either because the buyer is inactive in the period or because the buyer chooses to visit another seller. This assumption keeps the analysis tractable by reducing an individual's history that is relevant for choices from potentially an infinite sequence to $\{0,1\} .^{8}$

The fraction of related sellers, denoted $\rho$, is an endogenous aggregate state variable. Because each related seller has one and only one related buyer, the number of related buyers in the market is equal to $\rho M$, and the expected number of active related buyers is $\lambda \rho M$. The number of unrelated buyers is $N-\rho M$ and the expected number of active unrelated buyers is $\lambda(N-\rho M)$. I will verify later that $\rho<\min \{1, b\}$ in the equilibrium; that is, some sellers are unrelated to any buyer and some buyers are unrelated to any seller.

\subsection{A buyer's decision and payoff}

Denote a buyer's type as $i \in\{0,1\}$, where a buyer of $i=1$ has a related seller and a buyer of type $i=0$ does not. For a type-0 buyer, denote the type of the seller whom he can visit as $j \in\{0,1\}$, where a seller $j=1$ has a related buyer and a seller of type $j=0$ does not. For a type- 1 buyer, denote the type of the seller whom he can visit as $j \in\{0,1, s\}$, where $j=s$ is the particular seller related to the buyer and $j=1$ is a seller related to someone else. When active, a type- $i$ buyer chooses the probability $\theta_{i j}(\rho, p) \in[0,1]$ with which the buyer visits each individual type- $j$ seller who posts price $p$. Let $v_{i j}(\rho, p)$ denote the value to an active type- $i$ buyer from such a visit. Let $V_{i}^{a}(\rho)$ denote the maximum value that an active type- $i$ buyer can obtain in the market, and refer to it as the market value for such a buyer. Clearly, $v_{i j}(\rho, p) \leq V_{i}^{a}(\rho)$ for all $i j \in\{00,01,10,11,1 s\}$. An active type- $i$

\footnotetext{
${ }^{8}$ The model can be generalized to allow a related seller to keep the relationship with a positive probability if the related buyer is inactive and if no other buyer visits the seller in the period. This extension requires a buyer's taste shock to be public information. If the realization of a buyer's taste shock is private information, it may be rational for a seller to terminate a relationship when the related buyer does not show up. However, explicitly modelling this decision under private information is complicated.
} 
buyer's optimal decision satisfies: $\theta_{i j}(\rho, p)=0$ if $v_{i j}(\rho, p)<V_{i}^{a}(\rho)$, and $\theta_{i j}(\rho, p) \in[0,1]$ if $v_{i j}(\rho, p)=V_{i}^{a}(\rho)$. Let $P_{0}$ be the set of prices posted by all unrelated sellers and $P_{1}$ by all related sellers. The market value for an active buyer is

$$
\begin{aligned}
& V_{0}^{a}(\rho)=\max _{j \in\{0,1\}}\left[\max _{p \in P_{j}} v_{0 j}(\rho, p)\right], \\
& V_{1}^{a}(\rho)=\max \left\{v_{1 s}\left(\rho, p_{1}\right), \max _{j \in\{0,1\}}\left[\max _{p \in P_{j}} v_{1 j}(\rho, p)\right]\right\},
\end{aligned}
$$

Note that $\theta$ is the probability that a buyer visits an individual seller. In the limit $M, N \rightarrow \infty, \theta_{i j}$ approaches zero, except for $j=s$. To characterize a buyer's strategy in the limit, I use the queue length, which is the expected number of visitors to a seller. In this limit, the number of active and related buyers is $\lambda \rho M$, and the number of active and unrelated buyers is $\lambda(N-\rho M)$. For $j \in\{0,1\}$, the queue length of type- 1 buyers visiting a type- $j$ seller who posts price $p$ is $q_{1 j}(\rho, p)=\lambda \rho M \theta_{1 j}(\rho, p)$, and the queue length of type-0 buyers visiting a type- $j$ seller is $q_{0 j}(\rho, p)=\lambda(N-\rho M) \theta_{0 j}(\rho, p){ }^{9}$ Queue lengths should satisfy the constraint that a buyer's visiting probabilities add up to one across the sellers. For a type- 1 buyer, this constraint is: $\theta_{1 s}+(\rho M-1) \theta_{11}+(1-\rho) M \theta_{10}=1$. In the limit $M, N \rightarrow \infty$, this constraint becomes:

$$
\rho q_{11}+(1-\rho) q_{10}=\left(1-\theta_{1 s}\right) \rho \lambda
$$

Similarly, for a type-0 buyer, $\rho M \theta_{01}+(1-\rho) M \theta_{00}=1$, and so

$$
\rho q_{01}+(1-\rho) q_{00}=(b-\rho) \lambda .
$$

With the queue length, I can express buyers' optimal decisions as

$$
\begin{aligned}
& \theta_{1 s}(\rho, p) \geq 0 \text { and } v_{1 s}(\rho, p) \leq V_{1}^{a}(\rho), \\
& q_{i 1}(\rho, p) \geq 0 \text { and } v_{i 1}(\rho, p) \leq V_{i}^{a}(\rho), \quad i \in\{0,1\}
\end{aligned}
$$

\footnotetext{
${ }^{9}$ As it is clear from this definition of the queue length, I follow the literature on directed search to focus on the equilibrium where all buyers of the same type respond to a seller's price (including deviations from an equilibrium) in the same way (see Peters, 1991).
} 


$$
q_{i 0}(\rho, p) \geq 0 \text { and } v_{i 0}(\rho, p) \leq V_{i}^{a}(\rho), \quad i \in\{0,1\} .
$$

The two inequalities on each line hold with complementary slackness.

Let me calculate buyers' value functions. First, denote $V_{i}(\rho)$ as a type- $i$ buyer's value function at the end of the previous period. ${ }^{10}$ Then,

$$
V_{i}(\rho)=\frac{1}{1+r}\left[\lambda V_{i}^{a}(\rho)+(1-\lambda) V_{0}\left(\rho_{+1}\right)\right], \quad i \in\{0,1\} .
$$

The subscript "+1" indicates next period. This equation is intuitive. When a type- $i$ buyer at the end of the previous period looked forward, he expected to be active in the current period with probability $\lambda$, in which case his value function is $V_{i}^{a}(\rho)$, and he expected to be inactive in the current period with probability $1-\lambda$, in which case he becomes unrelated and obtains the value at the end of the current period, $V_{0}\left(\rho_{+1}\right)$. Discounting the expected value of these two cases yields the value at the end of the previous period.

Second, I calculate $v_{1 j}$, the value for a type- 1 buyer when visiting a type- $j$ seller. If the buyer visits seller $s$, the buyer will be chosen by the seller with certainty. In this case, the buyer will obtain net utility from consumption in the period, $U-p_{1}$, and will have a continuation value $V_{1}\left(\rho_{+1}\right)$ at the end of the period. If $p$ is the price posted by the related seller, then the buyer's value of visiting the related seller is

$$
v_{1 s}(\rho, p)=U-p+V_{1}\left(\rho_{+1}\right) .
$$

If the buyer visits a seller who is not related to the buyer, then the buyer's value is the same as the value for a buyer who visits the same seller but who is not related to any seller. That is, the following equalities hold for all $p$ :

$$
v_{11}(\rho, p)=v_{01}(\rho, p) \quad \text { and } \quad v_{10}(\rho, p)=v_{00}(\rho, p)
$$

Third, I calculate $v_{00}(\rho, p)$, the value for a type- 0 buyer who visits a type- 0 seller posting price $p$. Label the seller $A$. The queue length of type- $i$ buyers visiting seller $A$ is $q_{i 0}$, where

\footnotetext{
${ }^{10}$ The fraction of sellers who are related to some buyers at the end of the previous period is the same as that at the beginning of the current period, and there is no uncertainty about this aggregate state. Also, since an individual's state variable has only a finite number of values, I simplify the notation by putting it as a subscript instead of an argument of the value function.
} 
$q_{i 0}=q_{i 0}(\rho, p)$ for $i \in\{0,1\}$, and the total queue length of buyers visiting seller $A$ is $q_{10}+q_{00}$. This is the expected number of visitors to seller $A$. The actual number of visitors is a random variable generated by buyers' visiting probabilities, $\theta_{10}(\rho, p)$ and $\theta_{00}(\rho, p)$. The probability that seller $A$ has at least one visitor is $1-e^{-\left(q_{10}+q_{00}\right)}$. Conditional on having at least one visitor, seller $A$ randomly chooses one visitor to trade with, and each visitor is chosen with the same probability. The unconditional probability that the particular buyer in the discussion is chosen is $\frac{1-e^{-\left(q_{10}+q_{00}\right)}}{q_{10}+q_{00}}$ (see Shi, 2011, for a derivation). With a trade, the buyer obtains utility $U-p$ in the period. In addition, the buyer becomes related to the seller, and the relationship changes the value for the buyer by $V_{1}\left(\rho_{+1}\right)-V_{0}\left(\rho_{+1}\right)$. Denote the buyer's surplus as $D_{b}\left(\rho_{+1}, p\right)=U-p+V_{1}\left(\rho_{+1}\right)-V_{0}\left(\rho_{+1}\right)$. Then,

$$
v_{00}(\rho, p)=\frac{1-e^{-\left(q_{10}+q_{00}\right)}}{q_{10}+q_{00}} D_{b}\left(\rho_{+1}, p\right)+V_{0}\left(\rho_{+1}\right)
$$

where $q_{i 0}=q_{i 0}(\rho, p)$ for $i \in\{0,1\}$.

Finally, consider a type-0 buyer who visits a type-1 seller posting price $p$. The seller trades with an unrelated buyer only when the seller's related buyer does not visit, which occurs with probability $\left(1-\lambda \theta_{1 s}\right)$. In this case, the particular type-0 buyer will be chosen with probability $\frac{1-e^{-\left(q_{11}+q_{01}\right)}}{q_{11}+q_{01}}$, since the queue length of unrelated buyers visiting the seller is $q_{11}+q_{01}$. Thus, the buyer's value of visiting a type- 1 seller is:

$$
v_{01}(\rho, p)=\left(1-\lambda \theta_{1 s}\right) \frac{1-e^{-\left(q_{11}+q_{01}\right)}}{q_{11}+q_{01}} D_{b}\left(\rho_{+1}, p\right)+V_{0}\left(\rho_{+1}\right),
$$

where $q_{i 1}=q_{i 1}(\rho, p)$ for $i \in\{0,1\}$, and $\theta_{1 s}=\theta_{1 s}(\rho, p)$.

\subsection{A seller's decision and payoff}

In a period, a seller is either related (type-1) or unrelated (type-0). For $j \in\{0,1\}$, let $J_{j}(\rho)$ be the value function of a type- $j$ seller, which is measured at the end of the previous period. To characterize a seller's decision, consider first a type-0 seller who posts a price $p_{0}$. Recall the assumption that a seller must set a price before knowing which buyer is active. There are $\rho M$ type- 1 buyers and, taking into account the probability that a buyer is active, each of these buyers visits the particular type- 0 seller with probability $\lambda \theta_{10}\left(\rho, p_{0}\right)$. 
There are $(N-\rho M)$ type-0 buyers each visiting the seller with probability $\lambda \theta_{00}\left(\rho, p_{0}\right)$. In the limit $M, N \rightarrow \infty$, the probability that the seller gets a buyer is:

$$
1-\left(1-\lambda \theta_{10}\right)^{\rho M}\left(1-\lambda \theta_{00}\right)^{N-\rho M} \rightarrow 1-e^{-\left(q_{10}+q_{00}\right)},
$$

where $\theta_{i 0}=\theta_{i 0}\left(\rho, p_{0}\right)$ and $q_{i 0}=q_{i 0}\left(\rho, p_{0}\right)$ for $i \in\{0,1\}$. When the seller trades, the current profit is $p_{0}-c$ and, relative to no trading, the seller's value at the end of the period changes by $\left[J_{1}\left(\rho_{+1}\right)-J_{0}\left(\rho_{+1}\right)\right]$. Let $D_{s}\left(\rho_{+1}, p_{0}\right)=p_{0}-c+J_{1}\left(\rho_{+1}\right)-J_{0}\left(\rho_{+1}\right)$ denote the seller's surplus. Then, the seller's value function obeys:

$$
\begin{aligned}
J_{0}(\rho) & =\frac{1}{1+r} \max _{p_{0}}\left\{\left[1-e^{-\left(q_{10}+q_{00}\right)}\right] D_{s}\left(\rho_{+1}, p_{0}\right)+J_{0}\left(\rho_{+1}\right)\right\} \\
\text { s.t. } & (2.6), \quad \text { where } q_{i 0}=q_{i 0}\left(\rho, p_{0}\right), i \in\{0,1\} .
\end{aligned}
$$

By incorporating (2.6) as a constraint, the seller explicitly takes into account the effect of the price choice on the queue length of visitors.

Next consider a type- 1 seller who posts a price $p_{1}$. The related buyer visits the seller with probability $\lambda \theta_{1 s}\left(\rho, p_{1}\right)$. A buyer whose related seller is someone else visits the seller with probability $\lambda \theta_{11}\left(\rho, p_{1}\right)$, and an unrelated buyer visits the seller with probability $\lambda \theta_{01}\left(\rho, p_{1}\right)$. Taking the limit $M, N \rightarrow \infty$ and suppressing the arguments $\left(\rho, p_{1}\right)$ of $\theta_{1 s}, q_{11}$ and $q_{01}, \mathrm{I}$ compute the probability that the seller has a trade as

$$
1-\left(1-\lambda \theta_{1 s}\right)\left(1-\lambda \theta_{11}\right)^{\rho M}\left(1-\lambda \theta_{01}\right)^{N-\rho M-1} \rightarrow 1-\left(1-\lambda \theta_{1 s}\right) e^{-\left(q_{11}+q_{01}\right)} .
$$

Let $D_{s}\left(\rho_{+1}, p_{1}\right)=p_{1}-c+J_{1}\left(\rho_{+1}\right)-J_{0}\left(\rho_{+1}\right)$ denote the seller's surplus. Then,

$$
\begin{aligned}
& J_{1}(\rho)=\frac{1}{1+r} \max _{p_{1}}\left\{\left[1-\left(1-\lambda \theta_{1 s}\right) e^{-\left(q_{11}+q_{01}\right)}\right] D_{s}\left(\rho_{+1}, p_{1}\right)+J_{0}\left(\rho_{+1}\right)\right\} \\
& \text { s.t. }(2.4) \text { and }(2.5), \quad \text { where }\left(\theta_{1 s}, q_{i 1}\right)=\left(\theta_{1 s}, q_{i 1}\right)\left(\rho, p_{1}\right), i \in\{0,1\} .
\end{aligned}
$$

Constraints (2.4) and (2.5) explicitly take into account the effect of the price choice on the related buyer's visiting probability and the queue length of unrelated buyers.

A type-1 seller can choose whether or not to give priority to the related buyer. If the seller does not give such priority, the seller will obtain the value $J_{0}$ as an unrelated seller does. It is optimal for a seller to give priority to the related buyer if and only if $J_{1} \geq J_{0}$. 


\subsection{Equilibrium definition}

With many sellers and buyers, the analysis is tractable only for equilibria which are symmetric in the sense that all individuals of the same type use the same strategy. In the definition of queue lengths, I have already assumed that all buyers of the same type respond to a seller's price (including deviations) in the same way. If all sellers of the same type also post the same terms of trade, they attract the same queue length of visitors. As explained by Burdett et al. (2001), the symmetric equilibrium is a reasonable object to focus on in a large market without coordination. In the symmetric equilibrium, the set of prices posted by type- $j$ sellers is $P_{j}=\left\{p_{j}\right\}$, where $j \in\{0,1\}$. I will suppress the arguments $\left(\rho, p_{0}\right)$ of $\left(\theta_{i 0}, q_{i 0}, v_{i 0}\right)$ and $\left(\rho, p_{1}\right)$ of $\left(\theta_{i 1}, \theta_{1 s}, q_{i 1}, v_{i 1}, v_{1 s}\right)$, where $i \in\{0,1\}$.

In the equilibrium, the fraction of related sellers, $\rho$, is endogenously determined by the flows of sellers between the two types. In a period, a seller becomes unrelated if the seller fails to sell, which occurs with probability $\left(1-\lambda \theta_{1 s}\right) e^{-\left(q_{11}+q_{01}\right)}$. An unrelated seller becomes related if the seller succeeds in trade, which occurs with probability $1-e^{-\left(q_{10}+q_{00}\right)}$. The fraction of related sellers changes between the current and the next period by

$$
\rho_{+1}-\rho=(1-\rho)\left[1-e^{-\left(q_{10}+q_{00}\right)}\right]-\rho\left(1-\lambda \theta_{1 s}\right) e^{-\left(q_{11}+q_{01}\right)} .
$$

An equilibrium with priority consists of buyers' choices $\theta_{i j}$, buyers' value functions $\left(V_{i}^{a}, V_{i}, v_{i j}\right)$ (where $j \in\{0,1, s\}$ for $i=1$, and $j \in\{0,1\}$ for $i=0$ ), sellers' choices $\left(p_{0}, p_{1}\right)$, sellers' value functions $\left(J_{0}, J_{1}\right)$, and the fraction of related sellers $\rho$ that satisfy:

(i) Buyers' choices $\theta_{i j}$ and implied queue lengths, $q_{1 j}=\lambda \rho M \theta_{1 j}$ and $q_{0 j}=\lambda(N-\rho M) \theta_{0 j}$, satisfy $(2.4)-(2.3)$, while the value functions $\left(V_{i}^{a}, V_{i}, v_{i j}\right)$ satisfy $(2.1)$ and $(2.7)-(2.11)$;

(ii) $p_{0}$ solves $(2.12), p_{1}$ solves $(2.13)$, and $\left(J_{0}, J_{1}\right)$ satisfy $(2.12),(2.13)$ and $J_{1} \geq J_{0}$;

(iii) $\rho$ satisfies $(2.14)$.

It is important to repeat that the inequality $J_{1} \geq J_{0}$ in (ii) requires it to be optimal for a seller to give priority to the related buyer. That is, the buyer-seller relationship is endogenous rather than being imposed. 


\section{Equilibrium Characterization}

\subsection{Narrowing down the set of equilibria}

Because $\rho<1$, it is easy to see that competition among sellers implies that a buyer enjoys a strictly positive surplus in an equilibrium. That is, $D_{b}\left(\rho_{+1}, p_{j}\right)>0$ for $j \in\{0,1\}$. The following lemma is proven in Appendix A:

Lemma 3.1. An equilibrium with priority satisfies: (i) $\theta_{11}=0, \theta_{1 s}=1$, and $\theta_{10}=0$; (ii) $\theta_{00}>0$; (iii) if $\theta_{01}>0$, then $v_{1 s}>v_{00}=v_{10}$; (iv) if $\theta_{01}=0$, then $v_{1 s}=v_{00}$.

The result $\theta_{11}=0$ in (i) says that a related buyer does not visit someone else's related seller. The reason is that, in comparison with the buyer's own related seller, someone else's related seller posts the same price and does not give priority to the buyer. With $\theta_{11}=0$, the result $\theta_{1 s}=1$ implies $\theta_{10}=0$. The result $\theta_{1 s}=1$ says that a related buyer chooses to visit only his related seller (say, seller $A$ ). This result is easy to understand if buyers unrelated to seller $A$ choose not to visit seller $A$. In this case, whenever $\theta_{1 s}<1$, seller $A$ can induce the related buyer to visit him with probability one by cutting the price slightly. Because this marginal change in the price has no consequence on other buyers' visiting probability to seller $A$, which remains at zero in this case, the discrete increase in the buyer's visiting probability increases the expected payoff to seller $A$. The result $\theta_{1 s}=1$ is also intuitive if buyers unrelated to seller $A$ choose to visit seller $A$ with positive probability. For an unrelated buyer to visit seller $A$, the buyer must obtain at least the same payoff from such a visit as visiting another seller. Since the buyer related to seller $A$ has the priority relative to an unrelated buyer, the related buyer obtains strictly higher payoff from visiting seller $A$ than visiting any other seller. Again, $\theta_{1 s}=1$ in this case. The result $\theta_{1 s}=1$ implies that, in the equilibrium, a relationship breaks up only when the related buyer receives a shock that makes him inactive in the period. ${ }^{11}$

\footnotetext{
${ }^{11}$ The assumption $\lambda<1$ is needed to prevent all sellers from being related in the steady state (see (2.14)). Endogenous breakups can be generated by allowing each buyer to contact two or more sellers in each period, in a way similar to labor-search models by Albrecht et al. (2006) and Galenianos and Kircher (2009). This extension is interesting but is left for future research. Also, see footnote 7.
} 
The result (ii) in Lemma 3.1 says that an unrelated buyer visits an unrelated seller with positive probability. This result is easy to understand: Since an unrelated seller does not discriminate the visitors, he can always attract unrelated buyers with a sufficiently low price. The result (iii) says that if unrelated buyers visit related sellers with positive probability, then the equilibrium payoff to a related buyer must be strictly higher than the payoff to an unrelated buyer. This result is explained as part of the explanation for (i) above. Finally, the result (iv) says that if unrelated buyers only visit unrelated sellers, then the two types of buyers must have the same payoff in the equilibrium. The reason is that when a related seller's only potential buyer is the related buyer, a price increase does not crowd out the seller's potential visitors. In this case, it is optimal for the related seller to raise price until the related buyer just slightly prefers visiting him.

With Lemma 3.1, there are only two possibilities of an equilibrium with priority, which differ in an unrelated buyer's optimal choice:

Partial mixing: An unrelated buyer mixes between the two types of sellers, i.e., $q_{01}>0$. Complete separation: An unrelated buyer visits only unrelated sellers, i.e., $q_{01}=0$. In both cases, the equilibrium satisfies $q_{00}>0, \theta_{1 s}=1, q_{10}=q_{11}=0, V_{1}^{a}(\rho)=$ $\max _{p} v_{1 s}(\rho, p)$, and $V_{0}^{a}(\rho)=\max _{p} v_{00}(\rho, p)$. Also, because $q_{10}=q_{11}=0$, I shorten the notation $q_{00}$ as $q_{0}$, and $q_{01}$ as $q_{1}$. The following lemma is proven in Appendix A:

Lemma 3.2. An equilibrium with partial mixing (and priority) does not exist.

To explain this result, note that an equilibrium with partial mixing requires a related seller to attract both the related buyer and unrelated buyers. Because an unrelated buyer is given a lower priority, a related seller must cut the price significantly below the price posted by an unrelated seller in order to attract unrelated buyers. This is not optimal for the related seller, because it defeats the purpose of benefiting from the relationship. Instead, the seller can increase the price until the related buyer remains just slightly better off by visiting him than visiting an unrelated seller. Although this high price attracts only the related buyer, it generates higher expected profit to the related seller than does the 
low price that attracts both types of buyers. With such pricing, the related seller squeezes all the rent from the relationship.

\subsection{The equilibrium}

I have shown that the only possible equilibrium with priority is the equilibrium with complete separation. To characterize the equilibrium, let me formulate a type-0 seller's maximization problem in (2.12) more explicitly as

$$
\begin{aligned}
(1+r) J_{0}(\rho) & =J_{0}\left(\rho_{+1}\right)+\max _{\left(p_{0}, q_{0}\right)}\left(1-e^{-q_{0}}\right) D_{s}\left(\rho_{+1}, p_{0}\right) \\
\text { s.t. } & \frac{1-e^{-q_{0}}}{q_{0}} D_{b}\left(\rho_{+1}, p_{0}\right)=V_{0}^{a}(\rho)-V_{0}\left(\rho_{+1}\right),
\end{aligned}
$$

where $D_{s}\left(\rho_{+1}, p_{0}\right)=p_{0}-c+J_{1}\left(\rho_{+1}\right)-J_{0}\left(\rho_{+1}\right)$ is the seller's surplus and $D_{b}\left(\rho_{+1}, p_{0}\right)=$ $U-p_{0}+V_{1}\left(\rho_{+1}\right)-V_{0}\left(\rho_{+1}\right)$ is the buyer's surplus. Here I have expressed the dependence of the queue length $q_{0}$ on the price $p_{0}$ explicitly as a constraint and added $q_{0}$ to the list of choices accordingly. The constraint is a form of (2.6) with $q_{0}>0$, which requires the seller to give a type- 0 visitor the same expected surplus as in the market. The seller takes as given the market value, $V_{0}^{a}(\rho)$, and future value functions, $\left(V_{0}, V_{1}, V_{0}^{a}, J_{0}, J_{1}\right)\left(\rho_{+1}\right)$. The first-order condition, the constraint and the Bellman equation in (3.1) imply:

$$
\begin{aligned}
& V_{0}^{a}(\rho)-V_{0}\left(\rho_{+1}\right)=e^{-q_{0}} \Delta\left(\rho_{+1}\right) \\
& p_{0}=U+V_{1}\left(\rho_{+1}\right)-V_{0}\left(\rho_{+1}\right)-\frac{q_{0}}{1-e^{-q_{0}}}\left[V_{0}^{a}(\rho)-V_{0}\left(\rho_{+1}\right)\right], \\
& (1+r) J_{0}(\rho)-J_{0}\left(\rho_{+1}\right)=\left[1-\left(1+q_{0}\right) e^{-q_{0}}\right] \Delta\left(\rho_{+1}\right),
\end{aligned}
$$

where $\Delta=D_{s}+D_{b}$ is the total surplus of the match given by

$$
\Delta\left(\rho_{+1}\right) \equiv U-c+V_{1}\left(\rho_{+1}\right)-V_{0}\left(\rho_{+1}\right)+J_{1}\left(\rho_{+1}\right)-J_{0}\left(\rho_{+1}\right)
$$

Note that the trading probability and the share of the surplus of a match with an unrelated seller are endogenous and are functions of the queue length $q_{0}$ only. A buyer's probability of trade when visiting an unrelated seller is $\frac{1-e^{-q_{0}}}{q_{0}}$ and the buyer's share of the match surplus is $D_{b} / \Delta=\frac{q_{0}}{e^{q_{0}-1}}$. Both are decreasing functions of $q_{0}$ only. Thus, a buyer's share of the match surplus has a one-to-one positive relation to the buyer's 
trading probability. Similarly, an unrelated seller's trading probability and surplus share are increasing functions of $q_{0}$.

With complete separation, a type- 1 seller attracts only the related buyer $\left(\right.$ since $\left.q_{1}=0\right)$. Denote $\bar{p}$ as the price that makes the related buyer indifferent between visiting the related seller and visiting other sellers; i.e., $\bar{p}$ satisfies $v_{1 s}(\rho, \bar{p})=V_{0}^{a}(\rho)$. As explained after Lemma 3.2 , the optimal price for attracting only the related buyer is $\bar{p}-\varepsilon$, where $\varepsilon>0$ is arbitrarily small. For convenience, I will simply refer to $\bar{p}$ as a type-1 seller's optimal choice of the price. Solving the related buyer's indifference condition, I get:

$$
\bar{p}=U+V_{1}\left(\rho_{+1}\right)-V_{0}^{a}(\rho) .
$$

Because $\bar{p}$ does not attract any type-0 buyer, a type-1 seller's value function satisfies:

$$
(1+r) J_{1}(\rho)=J_{0}\left(\rho_{+1}\right)+\lambda\left[\bar{p}-c+J_{1}\left(\rho_{+1}\right)-J_{0}\left(\rho_{+1}\right)\right] .
$$

For complete separation to be an equilibrium, a type-1 seller should not gain from deviating to a price that attracts both the related buyer and unrelated buyers. Among all prices that attract both types of buyers, the best price $p_{1}$ and the implied queue length $q_{1}$ solve the maximization problem in (2.13) which can be rewritten as

$$
(1+r) J_{1}(\rho)=J_{0}\left(\rho_{+1}\right)+\max _{\left(p_{1}, q_{1}\right)}\left[1-(1-\lambda) e^{-q_{1}}\right] D_{s}\left(\rho_{+1}, p_{1}\right)
$$

subject to

$$
(1-\lambda) \frac{1-e^{-q_{1}}}{q_{1}} D_{b}\left(\rho_{+1}, p_{1}\right)=V_{0}^{a}(\rho)-V_{0}\left(\rho_{+1}\right),
$$

where $D_{s}\left(\rho_{+1}, p_{1}\right)=p_{1}-c+J_{1}\left(\rho_{+1}\right)-J_{0}\left(\rho_{+1}\right)$ is the seller's surplus and $D_{b}\left(\rho_{+1}, p_{1}\right)=$ $U-p_{1}+V_{1}\left(\rho_{+1}\right)-V_{0}\left(\rho_{+1}\right)$ is the buyer's surplus. As a form of (2.5) with $q_{1}>0,(3.8)$ requires that if $p_{1}$ attracts unrelated buyers, then the expected surplus to such a buyer should be equal to the buyer's expected surplus in the market. Denote the solution for $\left(p_{1}, q_{1}\right)$ to the problem in $(3.7)$ as $\left(\tilde{p}_{1}, \tilde{q}_{1}\right)$. For a related seller, attracting both types of buyers is weakly dominated by attracting only the related buyer if and only if the expected surplus generated by $\left(\tilde{p}_{1}, \tilde{q}_{1}\right)$ is not greater than that generated by $\bar{p}$, as expressed below:

$$
\left[1-(1-\lambda) e^{-\tilde{q}_{1}}\right] D_{s}\left(\rho_{+1}, \tilde{p}_{1}\right) \leq \lambda D_{s}\left(\rho_{+1}, \bar{p}\right) .
$$


An equilibrium with complete separation must also satisfy $J_{1}(\rho) \geq J_{0}(\rho)$ in order for a type-1 seller to give priority to the related buyer. Moreover, $q_{0}$ and $\rho$ need to be determined and verified to satisfy $q_{0}>0$ and $\rho \in(0, \min \{1, b\})$. With complete separation, the addingup constraint (2.3) yields:

$$
q_{0}=H(\rho) \equiv \lambda(b-\rho) /(1-\rho) .
$$

Then, the law of motion of $\rho$ given by (2.14) becomes:

$$
\rho_{+1}=G(\rho) \equiv \lambda \rho+(1-\rho)\left[1-e^{-H(\rho)}\right] .
$$

Note that (3.10) and (3.11) are independent of variables other than $\left(\rho, q_{0}\right)$. Thus, the steady state and the dynamics of $\left(\rho, q_{0}\right)$ can be solved from these two equations without the help of any other equilibrium relations.

To sum up, an equilibrium (with complete separation) consists of prices $\left(p_{0}, \bar{p}\right)$, queue length $q_{0}$, value functions $\left(J_{0}(\rho), J_{1}(\rho)\right)$ and the fraction of related sellers $\rho$ that satisfy (3.2), (3.3), (3.5), (3.6), (3.9), $J_{1}(\rho) \geq J_{0}(\rho),(3.10)$ and (3.11). Adding the superscript * to the variables in the steady state, I prove the following proposition in Appendix B:

Proposition 3.3. (i) There exists $B(\lambda)>0$, defined in Appendix B, such that the steady state exists if and only if $b \leq B(\lambda)$. The steady state is unique.

(ii) The steady state is locally stable. In the equilibrium, $\rho$ and $q_{0}$ depend only on $(\lambda, b)$. Moreover, $0<\rho^{*}<\min \{1, b \lambda\}, q_{0}^{*}>0, \frac{d \rho^{*}}{d b}>0, \frac{d q_{0}^{*}}{d b}>0$, and $\frac{d \rho^{*}}{d \lambda}>0$.

(iii) For $\rho$ close to $\rho^{*}$, the equilibrium satisfies $\Delta(\rho)>0$ and the following conditions:

$$
\begin{aligned}
& p_{0}=U-\frac{q_{0} e^{-q_{0}}}{1-e^{-q_{0}}} \Delta\left(\rho_{+1}\right), \\
& p_{1}=\bar{p}=U-e^{-q_{0}} \Delta\left(\rho_{+1}\right)>\max \left\{p_{0}, c\right\}, \\
& V_{1}(\rho)=V_{0}(\rho)=\frac{1}{1+r}\left[V_{0}\left(\rho_{+1}\right)+\lambda e^{-q_{0}} \Delta\left(\rho_{+1}\right)\right], \\
& \Delta(\rho)=U-c+\frac{1}{1+r}\left[\lambda\left(1-e^{-q_{0}}\right)-1+\left(1+q_{0}\right) e^{-q_{0}}\right] \Delta\left(\rho_{+1}\right),
\end{aligned}
$$

where $q_{0}=H(\rho)$ and $\rho_{+1}=G(\rho)$ are given by (3.10) and (3.11). 
It is intuitive that the steady state with complete separation exists if and only if the buyer/seller ratio is not too high, as expressed by the condition $b \leq B(\lambda)$. When the number of buyers for each seller is small, it is difficult for a seller to obtain a trade. In this case, it is optimal for a seller to give priority to his related buyer so as to guarantee a trade whenever the buyer is active. Moreover, when the buyer/seller ratio is low, the price charged by an unrelated seller is likely to be low. Competing against such sellers for unrelated buyers is not optimal for a related seller, because it would require the seller to cut price sufficiently to compensate unrelated buyers for the low priority. Thus, the equilibrium in this case indeed has complete separation between related and unrelated individuals. On the other hand, if the buyer/seller ratio is high, getting a buyer is relatively easy for a seller, in which case it is optimal for a seller to treat all buyers equally.

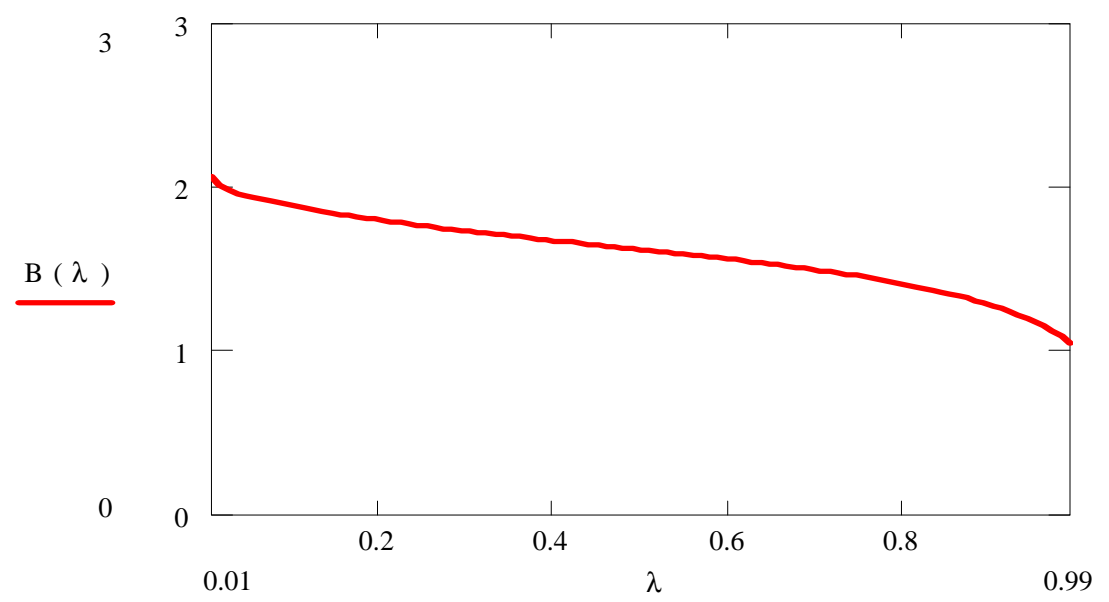

Figure 1. The critical level $B(\lambda)$ of the buyer/seller ratio

Figure 1 depicts the upper bound $B(\lambda)$. It is clear that $B(\lambda)>1$ for all $\lambda \in(0,1)$, and so a sufficient condition for the equilibrium to exist is that the number of buyers does not exceed the number of sellers. Moreover, $B^{\prime}(\lambda)<0$ for all $\lambda \in(0,1)$; that is, a higher $\lambda$ makes the equilibrium with complete separation less likely to exist for any given $b$. This negative effect of $\lambda$ on existence is the result of two opposing effects. The first is the general effect that a higher $\lambda$ increases the demand. This effect makes a relationship less valuable, reduces $B$, and makes an equilibrium with complete separation less likely to exist. The second effect is that a higher $\lambda$ tilts the demand toward related sellers by 
increasing the probability that a seller's related buyer will be active in the period. This effect makes a relationship more valuable, increases $B$, and makes the steady state with complete separation more likely to exist. The general effect of $\lambda$ dominates the demandtilting effect in determining existence of the equilibrium. ${ }^{12}$

The unique steady state is locally stable; that is, there is a unique saddle path along which the fraction of related sellers converges to the steady state level $\rho^{*}$. If $\rho>\rho^{*}$, the flow of related sellers who lose relationships in a period is greater than the flow of unrelated sellers who acquire relationships through trade. In this case, there is a positive net flow of sellers out of relationships, and so the fraction of related sellers falls toward the steady state. On the other hand, if $\rho<\rho^{*}$, the flow of related sellers who lose relationships is smaller than the flow of unrelated sellers who acquire relationships through trade. In this case, the fraction of related sellers increases toward the steady state.

The fraction $\rho$ and the queue length $q_{0}$ depend only on the extensive margin of the demand, $(b, \lambda)$, but not on other parameters such as $(c, U)$. This is not surprising because $\rho$ and $q_{0}$ are determined by equilibrium requirements on the matching rates which depend only on the extensive margin of the market. Specifically, given $(\lambda, b)$ and the composition of sellers, $\rho$, the queue length $q_{0}$ is uniquely pinned down by the requirement that a buyer's visiting probabilities across the sellers should add up to one. Conversely, given $(\lambda, b)$ and $q_{0}$, each seller's matching rate is uniquely determined. These two relations are given above as $q_{0}=H(\rho)$ and $\rho_{+1}=G(\rho)$, which uniquely determine the dynamics of $\rho$ and $q_{0}$. Because the only parameters in these relations are $(\lambda, b)$, the solutions for $\left(\rho, q_{0}\right)$ to these relations depend only on $(\lambda, b)$ and not on other parameters such as $c$ and $U$.

It is intuitive that the fraction of related sellers in the steady state increases in the two dimensions of the extensive margin of the demand, $b$ and $\lambda$. A higher $b$ or $\lambda$ leads

\footnotetext{
${ }^{12}$ The upper bound $B$ depends only on $\lambda$ and not on other parameters such as the cost $c$ and the utility $U$. To see why, note that an individual seller's decisions on whether or not to give priority to the related buyer and whether to attract one type or two types of buyers affect the seller's expected share of the match surplus but they do not affect the size of the surplus (which is given as $\Delta$ ). Thus, whether an equilibrium with complete separation exists depends only on the features of the expected surplus share. As I will explain below, this share in the equilibrium depends only on the extensive margin of the demand, which is summarized by $(\lambda, b)$. As a result, $B$ is a function of $\lambda$ only.
} 
to a larger number of trades in each period. Because a trade turns an unrelated seller into a related one, the increase in the number of trades increases the fraction of related sellers in the equilibrium. It is also intuitive that a higher buyer/seller ratio increases the queue length of buyers for an unrelated seller in the steady state, $q_{0}^{*}$, because the larger number of buyers must be eventually allocated to the sellers. However, it is ambiguous whether a higher $\lambda$ increases $q_{0}^{*}$. On the one hand, a higher $\lambda$ increases the demand per seller, which has a positive effect on $q_{0}^{*}$. On the other hand, a higher $\lambda$ means that a larger fraction of buyers are related to some sellers, and so the queue length of buyers for each unrelated seller is smaller. The overall effect of $\lambda$ on $q_{0}^{*}$ depends on the values of $\lambda$ and $b$ (see subsection 4.4 for an example).

\subsection{Relationship, the regular price and sales}

In each period, a related seller posts the regular price $p_{1}=\bar{p}$ and an unrelated seller posts the sale price $p_{0}<\bar{p}$. Over time, the price posted by a seller varies between the two prices as the seller's type changes. A seller posts the regular price as long as he has a related buyer and, once the seller loses the relationship, he holds a sale at price $p_{0}$ until he gains a relationship. The fact that an unrelated seller cuts the price to $p_{0}$ with an intention to revert to a higher price $p_{1}$ in the future justifies the interpretation of $p_{0}$ as a sale price. In addition, the two prices are not constant outside the steady state. Instead, they are functions of the fraction of related sellers in the market. As this aggregate state approaches the steady state, so do the two prices.

The consideration for holding a sale is intertemporal. By holding a sale, a seller intends to attract buyers and form a relationship, but the relationship will be paid off only in the future through a higher (regular) price. Moreover, the sale price can be lower than the marginal cost of the good, which can be verified with the formula of $p_{0}$ in (3.12). Specifically, when the rent to the seller from a relationship, measured by $J_{1}-J_{0}$, is large enough, an unrelated seller may find it optimal to incur the temporary loss of a markdown in order to form the relationship. In contrast, the regular price $p_{1}$ is always strictly higher than the marginal cost (see (3.13)). 
In the equilibrium, a seller's trading probability is likely to be positively related to price across seller types. This is particularly the case when $\lambda$ is close to one, in which case a related seller (who posts the high price) almost guarantees a trade by offering priority to the related buyer. The positive relationship across seller types does not contradict the negative relationship between the two variables within each type of sellers that is predicted by a canonical model of directed search. In fact, the negative relationship with each seller type is critical for individuals' decisions, as characterized above. Nevertheless, it is worth noting that the type of a seller in this model is endogenously determined by the seller's trading history instead of an exogenous characteristic. Thus, if one only controls for exogenous characteristics in empirical work, he may not necessarily find a negative relationship between price and the seller's trading probability even when the market features directed search.

The equilibrium has precise predictions on the frequency, the duration and the price discount of sales. The number of trades is $M \rho \lambda$ at $p_{1}$, and $M(1-\rho)\left(1-e^{-q_{0}}\right)$ at $p_{0}$. Then, the frequency of trade at the sale price is

$$
d p r o b=\frac{(1-\rho)\left(1-e^{-q_{0}}\right)}{\rho \lambda+(1-\rho)\left(1-e^{-q_{0}}\right)} .
$$

When $\rho=\rho^{*}$, where $\rho^{*}$ is the steady state of (3.11), it is easy to verify that $d p r o b^{*}=1-\lambda$. The frequency of trade at the sale price in the steady state depends on $\lambda$ but not on $(b, c, U)$. This result is intuitive: because the motive for holding a sale is to gain a relationship with a buyer, how often a seller holds sales should depend only on how frequently the seller loses a relationship, which is $1-\lambda$.

Let dlength denote the expected duration of a sale. If a seller holds a sale in a period, the sale will continue next period if and only if the seller fails to trade in the current period, which occurs with probability $e^{-q_{0}}$. Thus, dlength $=1+e^{-q_{0}} \times$ dlength, and so

$$
\text { dlength }=\frac{1}{1-e^{-q_{0}}} .
$$

As explained for Proposition 3.3, $q_{0}$ depends only on the extensive margin of the demand, $(b, \lambda)$. Thus, the duration of a sale depends only on $(b, \lambda)$ and not on the intensive margin 
of the market. Moreover, $b$ and $\lambda$ can affect the sales duration differently. Because a higher buyer/seller ratio, $b$, increases $q_{0}$, it reduces the duration of a sale. In contrast, $\lambda$ affects the duration of a sale ambiguously: The duration decreases in $\lambda$ if and only if $q_{0}$ increases in $\lambda$, but $q_{0}$ may or may not increase in $\lambda$, as explained above.

Let dsize denote the percentage price discount of a sale. Then,

$$
\text { dsize }=1-\frac{p_{0}}{p_{1}}=\left(\frac{q_{0}}{1-e^{-q_{0}}}-1\right)\left[\frac{U e^{q_{0}}}{\Delta}-1\right]^{-1} .
$$

In contrast to the frequency and duration of a sale, the price discount depends on both the extensive and intensive margin of the market. It depends $(\lambda, b)$ through $\left(q_{0}, \Delta\right)$, and on $(c, U)$ through $U / \Delta$. For future use, I define the markup implied by each price as

$$
\operatorname{markup} 0=\frac{p_{0}}{c}-1, \quad \text { markup } 1=\frac{p_{1}}{c}-1 .
$$

Because the regular price is strictly higher than the cost (see (3.13)), the regular price always implies a positive markup. In contrast, the sale price can be a markdown instead of a markup, as explained above. Weighting each markup by the frequency of trade occurring at the associated price, I obtain the average markup as

$$
\text { markavg }=\text { dprob } \times \text { markup } 0+(1-d p r o b) \times \text { markup } 1
$$

Similarly, I can calculate the average price in the equilibrium.

\section{Comparative Statics and Numerical Examples}

In this section I examine the response of the steady state to changes in $(c, b, \lambda)$. A change in a parameter may also induce dynamics in the stock of relationships, $\rho$. However, the equilibrium converges to the new steady state relatively quickly (see Shi, 2011), and such dynamics are omitted here to economize on space. The superscript $*$ on steady-state variables will be suppressed whenever possible.

\subsection{Parameter values}

Table 1 lists the parameter values and the targets used to identify the parameters. These parameter values and targets are intended for a concrete illustration of equilibrium prop- 
erties. As such, they are only suggestive. The comparative statics in subsections 4.2-4.4 can be interpreted as sensitivity analyses on the parameters.

Table 1. Parameters and calibration targets

\begin{tabular}{|l|l|l|}
\hline parameter & value & target \\
\hline$r:$ discount rate & $7.545 \times 10^{-4}$ & annual discount rate $=0.04$ \\
\hline$U:$ utility level & 1 & normalization \\
\hline$\lambda:$ active prob. & 0.956 & frequency of sale price quotes $=0.15$ \\
\hline$b:$ buyer/seller ratio & 0.895 & average duration of a sale $=4$ weeks \\
\hline$c:$ marginal cost & 0.311 & percentage price discount of a sale $=0.28$ \\
\hline
\end{tabular}

The length of a period is one week. By setting the annual discount rate to $4 \%$, I determine the weekly discount rate $r$ through $(1+r)^{52}=1.04$. The utility of consuming a good is normalized to one. Next, I set the steady-state fraction of sale price quotes (not trades) to $1-\rho^{*}=0.15$ and the steady-state duration of a sale to 4 weeks. The fraction of sale price quotes is higher than the number in the microdata on the U.S. monthly CPI, which is 0.11 as reported by Klenow and Kryvtsov (2008). The duration of a sale is shorter than in the monthly data, which is 1.8 to 2.3 months as reported by Nakamura and Steinsson (2008). I choose the two targets to reflect the fact that some sales are much shorter than one month, which are likely to be under-sampled in the monthly data. ${ }^{13}$ These two targets solve $\rho^{*}$ and $q_{0}^{*}$. Then, I can retrieve $\lambda$ and $b$ from the steady-state version of (3.10) and (3.11), which are (B.1) and (B.2) in Appendix B. Note that $b$ is less than one, and so the condition $b \leq B(\lambda)$ under which the steady state exists is satisfied. Finally, I set the steady-state discount of a sale to $28 \%$, which lies between the number $25.1 \%$ reported by Klenow and Kryvtsov (2008) and the number 29.5\% reported by Nakamura and Steinsson (2008). With (3.18), this target determines $c$. The implied average price in the steady state is 0.346 and the average markup in the steady state is markavg* $=0.113$.

\footnotetext{
${ }^{13}$ To get a sense of the effect of time aggregation, note that Klenow and Kryvtsov (2008) report that $15 \%$ of all (monthly) price quotes for food items are sales. With daily data collected on a specific food item (bottled ketchup), Pesendorfer (2002) reports that $23 \%$ of prices fall in the range $\$ 0.99-\$ 1.19$, while $60 \%$ of all daily prices fall in the range $\$ 1.39$ - $\$ 1.49$. If the first range is regarded as the range of sale prices, then sale prices are at least $23 \%$ of all price quotes.
} 


\subsection{Steady-state response to changes in the cost}

The first experiment is a change in the marginal cost of a good, $c$. The identified value of $c$ is 0.311 . I vary $c$ from 0.1 to 0.9 . Most variables respond to $c$ in a predictable way. For example, the two prices $p_{1}$ and $p_{0}$ increase with $c$. The value of every individual falls with $c$, regardless of whether or not the individual is related in the market. Because $q_{0}$ and $\rho$ are independent of $c$ (see Proposition 3.3), the matching rates, the frequency of trade at the sale price and the duration of a sale are all independent of $c$ in the steady state.

The responses of the markups to the marginal cost are noteworthy. Figure 2 depicts steady-state markups as functions of $c$. The markup implied by the sale price, markup0, is negative for all values of $c$, and so the sale price is a markdown on the marginal cost. This markdown occurs because the buyer/seller ratio is noticeably less than one $(b=0.895)$, which makes a relationship important for a seller. By offering a markdown, a seller can attract buyers and acquire a relationship more quickly. At the baseline value of the cost, the markdown implied by the sale price is markup $0=-0.189$ and the markup implied by the regular price is markup $1=0.127$. The average markup is positive and close to the markup implied by the regular price, because a majority of trades take place at the regular price. The result that a sale is a markdown is consistent with the finding by Dutta et al. (2002) using scanner data from a supermarket chain.

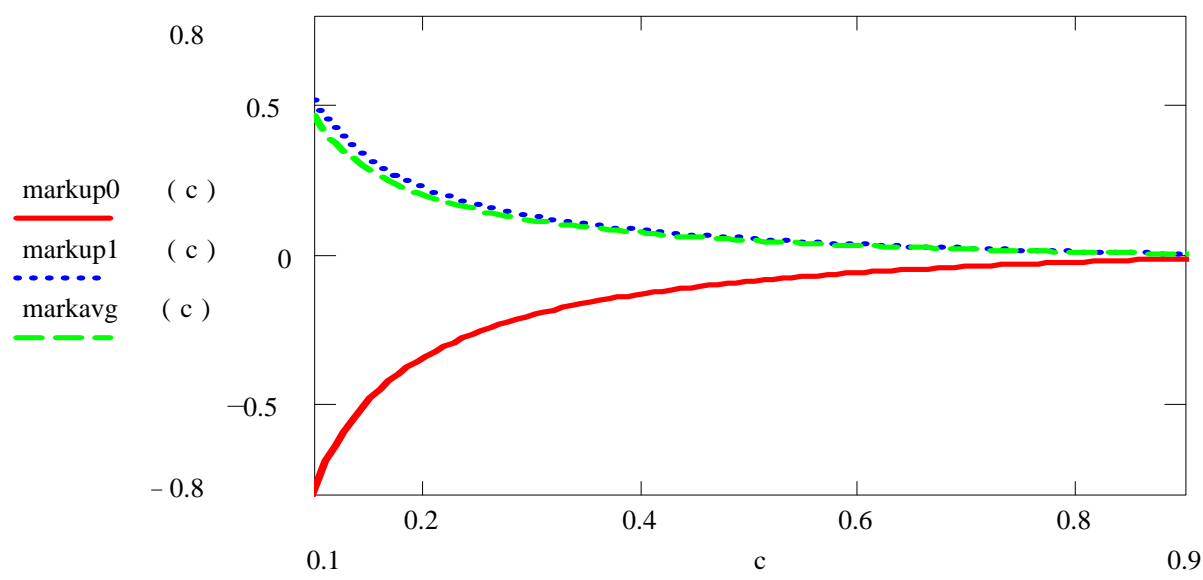

Figure 2. Responses of markups to the marginal cost $c$

The markdown and the markup are large when the cost is very low, and their absolute 
values decrease precipitously when the cost increases. For example, when the cost $c$ increases from 0.1 to 0.5 , the magnitude of the markdown falls from -0.765 to -0.085 , and the markup falls from 0.513 to 0.057 . When the cost is very low, the markdown and the markup are large because the potential gain to a seller from making a buyer related to him is large. As this gain decreases in the cost, the room for markups is reduced, and so is the need to use large markdowns to attract a buyer to build a relationship.

These responses of the markups to the cost have several implications. First, if customer relationship is important in the retail market, then markups change with the marginal cost, in contrast to the constant markup in macro models based on monopolistic competition. Second, across goods that differ in the cost and utility, the higher the difference $(U-c)$, the larger the difference between the regular price and the sale price. That is, goods with a higher profit margin have a higher variability in prices. Third, the percentage change in the regular price in response to the cost is less than that in the sale price. In this sense, the regular price is relatively more stable than the sale price. This difference exists because a related seller's trading probability is higher than an unrelated seller's. The same change in the price amounts to a larger change in expected profit for a related seller than for an unrelated seller. To cover the increased cost, only a smaller change in the regular price is needed than in the sale price.

\subsection{Steady-state response to changes in the buyer/seller ratio}

The second experiment is a change in the extensive margin of the demand through the buyer/seller ratio $b$. As demonstrated analytically in Proposition 3.3, an increase in $b$ increases the queue length of buyers for each unrelated seller, $q_{0}$, and increases the fraction of related sellers in the market, $\rho$. As a result, the duration of a sale decreases. For $b$ ranging from 0.45 to 1.1, Figure 3.1 depicts steady-state markups, and Figure 3.2 depicts the duration and the price discount of a sale in the steady state. ${ }^{14}$

The following features are notable. First, the sale price is a markdown for all $b \leq 0.984$, and the largest markdown occurs at $b=0.92$. When $b$ continues to increase above 0.92 ,

\footnotetext{
${ }^{14}$ The condition $b \leq B(\lambda)$ for the equilibrium to exist continues to hold.
} 
a seller's incentive to use markdowns to attract buyers becomes increasingly weak, and so the sale price generates a positive markup eventually. Second, the markup implied by the regular price increases in $b$ for all values of $b$. Together with the behavior of the sale price, this implies that the percentage price discount of a sale, dsize, has a hump-shaped dependence on $b$, as depicted in Figure 3.2. This price discount increases when $b$ increases from low values, reaches the maximum around $b=0.98$ and then starts to fall as $b$ continues to increase. Third, in contrast to the non-monotonic dependence of the markdown and the price discount of a sale on $b$, the duration of the discount, dlength, monotonically decreases in $b$, as depicted in Figure 3.2. This is because the duration of the discount is a decreasing function of the queue length of buyers for each unrelated seller and, as shown in Proposition 3.3, this queue length increases monotonically with the buyer/seller ratio. This monotonic response of the duration of a sale is a more reliable indicator of market conditions than the non-monotonic responses of prices and markups.

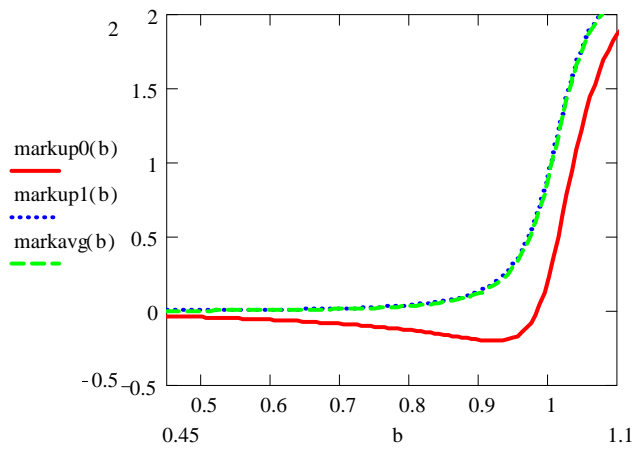

Figure 3.1

Markups

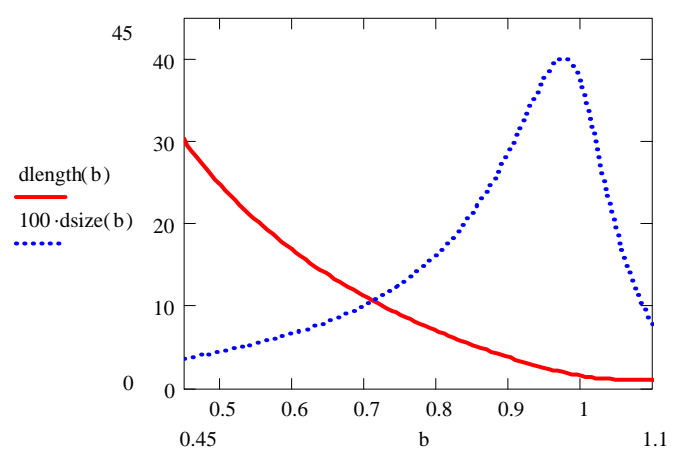

Figure 3.2

Duration and size of a sale

Note that reductions in $b$ generate large, non-linear increases in the duration of a sale. For example, when $b$ decreases from the baseline value 0.895 to 0.7 and then to 0.5 , the duration of a sale increases from 4 weeks to 11.3 weeks and then to 24.8 weeks.

\subsection{Steady-state response to changes in $\lambda$}

The third experiment is a change in the probability that a buyer is active in a period, $\lambda$. In contrast to an increase in $b$, which increases the demand for all sellers evenly, an increase in $\lambda$ has the additional effect of tilting the demand toward related sellers. For $\lambda$ ranging 
from 0.1 to 0.95 , Figure 4.1 depicts the queue length of buyers per unrelated seller, $q_{0}$, and the duration of a sale in the steady state, while Figure 4.2 depicts the markups in the steady state. The queue length $q_{0}$ depends on $\lambda$ non-monotonically: it increases in $\lambda$ when $\lambda$ increases from low values, reaches the maximum around $\lambda=0.78$, and then decreases as $\lambda$ increases further. This means that at low values of $\lambda$, the general effect of a higher $\lambda$ in increasing the demand dominates but at high values of $\lambda$, the effect of a higher $\lambda$ in shifting the demand to related sellers dominates. Because the duration of a sale is a decreasing function of $q_{0}$, the hump-shaped response of $q_{0}$ to $\lambda$ implies that the duration of a sale has a U-shaped dependence on $\lambda$. That is, the duration of a sale is higher at both high and low values of $\lambda$ than at intermediate values of $\lambda$.

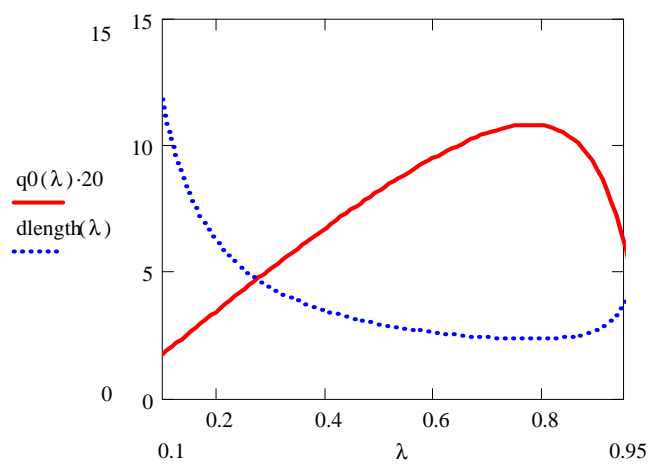

Figure 4.1

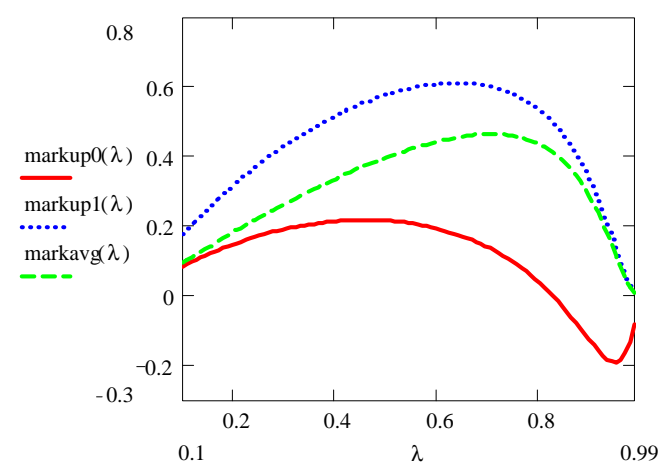

Figure 4.2

Queue length and duration of a sale

The markups also change with $\lambda$ non-monotonically. At low values of $\lambda$, the two markups both increase in $\lambda$. The markup implied by the sale price reaches the maximum around $\lambda=0.45$, after which it falls and eventually becomes negative. The markup implied by the regular price continues to increase until $\lambda=0.66$, after which it also starts to fall but stays positive. As a result, the price discount of a sale (not depicted) has hump-shaped dependence on $\lambda$. These responses of the markups reflect the fact that the return to a seller from a relationship is larger at intermediate values of $\lambda$ than at both high and low values of $\lambda$. This return is low at low values of $\lambda$ because the related buyer is unlikely to be active in the future. This return is also low at high values of $\lambda$ because, when almost all sellers have a related buyer, competition among them drives down the regular price. In contrast, at intermediate values of $\lambda$, there is a sizable benefit of giving priority to the related buyer 
and charging a high regular price. Reflecting this non-monotonic dependence of the benefit of a relationship, a seller's value function (not depicted here) has hump-shaped dependence on $\lambda$, although a buyer's value monotonically increases in $\lambda$.

It is remarkable that prices and markups can fall when the demand increases through $\lambda$. This result offers an explanation for the finding by Chevalier et al. (2003) that prices of particular items in a supermarket chain typically fall when the items experience peak seasonal demand. Specifically, the particular items are likely demanded by a store's regular customers. An increase in the demand for such items increases competition among the stores for the regular customers and reduces prices.

\section{Free Entry of Sellers}

I have assumed so far that the buyer/seller ratio $b$ is fixed. Now I endogenize $b$ by assuming that there is free entry of sellers into the market. Let $k$ be the cost of entry and, to simplify various expressions, let it be measured at the end of the previous period. If a seller pays the cost $k$ to enter the market, the seller is unrelated to any buyer, and so the seller's value function is $J_{0}(\rho)$, also measured at the end of the previous period. Free entry implies that the net value of an entry seller is zero, i.e., $J_{0}(\rho)=k$. This condition determines the buyer/seller ratio, $b$, since $J_{0}(\rho)$ depends on $b$. The following proposition states the properties of the steady state with an endogenous $b$ (see Shi, 2011, for a proof):

Proposition 5.1. (i) There exists $K>0$ such that a steady state with endogenous $b$ and complete separation exists if and only if $k \leq K$. The steady state is unique.

(ii) In the steady state, $d q_{0}^{*} / d c>0, d \rho^{*} / d c>0, d b^{*} / d c>0$.

(iii) $d p_{0}^{*} / d c>0, d p_{1}^{*} / d c>0, d\left(p_{1}^{*}-p_{0}^{*}\right) / d c<0$, and $d\left(p_{1}^{*}-c\right) / d c<0$.

It is intuitive that the entry cost cannot be very high if a steady state with priority exists. If the entry cost is very high, then the expected value for an unrelated seller must also be high to cover the entry cost. This requires the matching rate for an unrelated seller to increase and, hence, the queue length of buyers per unrelated seller to increase. Since it 
is relatively easy in this case to have a trade as an unrelated seller, a seller finds it optimal to give no priority to the related buyer.

In contrast to the model with a fixed $b$, now an increase in $c$ affects $\left(b^{*}, q_{0}^{*}, \rho^{*}\right)$. These effects are easy to explain. Because an increase in the marginal cost reduces ex post profit, fewer sellers enter the market, and so the buyer/seller ratio, $b^{*}$, increases. For the marginal seller who enters the market (as an unrelated seller), the trading probability must increase in order for the seller to cover the entry cost. This requires the queue length per unrelated seller, $q_{0}^{*}$, to increase. As an unrelated seller succeeds in trade more likely than before, the fraction of related sellers in the steady state, $\rho^{*}$, increases. Note that because the increase in $c$ increases $q_{0}^{*}$, it reduces the duration of a sale.

Part (iii) of Proposition 5.1 reveals how the two prices change with $c$. The sale price increases with the cost by more than the regular price does, as in subsection 4.2. Thus, the increase in the cost reduces the percentage of the price discount. Also, the regular price increases by less than the cost does, which again reflects the feature that the regular price is relatively more stable with respect to the change in the cost. This result implies that the markup implied by the regular price falls as the cost increases.

On the quantitative side, I can calibrate the entry cost $k$ so that the steady-state buyer/seller ratio is equal to the one identified in Table 1 . With this value of $k$, the responses of the two markups to $c$ (not graphed here) are very close to the ones depicted in Figure 2 under a fixed $b$. The main change is that an increase in $c$ reduces the duration of a sale sizably when $b$ is endogenous. ${ }^{15}$ Moreover, an increase in $\lambda$ reduces $q_{0}^{*}$ and reduces the average markup for all values of $\lambda$, in contrast to the non-monotonic effects depicted in Figures 4.1 and 4.2 for a fixed $b$. This contrast arises from the fact that an increase in $\lambda$ induces new sellers to enter the market. Such entry reduces the expected number of buyers for an unrelated seller, intensifies competition among all sellers, and reduces the average markup. Thus, allowing for seller entry strengthens the earlier result that an increase in the demand through $\lambda$ can reduce prices and markups.

\footnotetext{
${ }^{15}$ An increase in the entry cost has similar effects to an increase in the cost of a good.
} 


\section{Conclusion}

I construct a model where informal customer relationship arises endogenously together with service priority and sales. The market consists of a large number of buyers and sellers. All sellers sell a homogeneous good and all buyers have the same publicly known valuation of the good. Buyers know the terms of trade offered by sellers before choosing which seller to visit. A buyer is related to a seller if the buyer just bought a good from the seller and the relationship is broken if the buyer fails to buy from the related seller. Sellers are restricted to offer the same price to all buyers, but they are allowed to give priority to their related buyers. I prove that there exists a unique equilibrium in which a seller gives priority to the related buyer and a buyer makes repeat purchases from the related seller. Over time, the price posted by a seller varies between two levels: The seller posts a (high) regular price to sell to the related buyer and, once the seller loses the relationship, the seller posts a (low) sale price to sell to unrelated buyers until he gains a relationship. The fraction of related sellers is endogenous in the equilibrium. Numerical examples illustrate that customer relationship can be an important driving force of individual price fluctuations. I also examine how market conditions affect the aggregate stock of relationships, markups, the size and the duration of a sale.

In addition to explaining customer relationship, this model has several features that can be useful for future work to build models where aggregate fluctuations are consistent with price dynamics at the micro level. The model has many buyers and sellers, it is dynamic, and it endogenizes customer relationship. The regular price is less responsive to shocks than the sale price in the model, which is consistent with the microdata. Moreover, the model shows the possibility that an increase in the particular extensive margin of the demand, $\lambda$, can reduce prices and markups. This result can be exploited further to obtain counter-cyclical markups that have been sought for in business cycle research which focuses on demand shocks. Finally, the model reveals that the duration of a sale responds to market conditions more accurately than prices do. A macro model with sales should explicitly incorporate the duration of a sale as part of price adjustments. 


\section{Appendix}

\section{A. Proofs of Lemmas 3.1 and 3.2}

Let me prove Lemma 3.1 first. Because $D_{b}\left(\rho_{+1}, p_{1}\right)>0$, comparing (2.8) and (2.11) yields $v_{1 s}>v_{01}\left(=v_{11}\right)$. Then, a type-1 buyer's optimal decision implies $\theta_{11}=0$, as stated in (i) of the lemma. Now, the results $\theta_{10}=0$ and $\theta_{1 s}=1$ are equivalent to each other. To prove $\theta_{1 s}=1$, there are two cases to consider. The first case has $v_{00} \leq v_{01}$. In this case, $v_{10}=v_{00} \leq v_{01}<v_{1 s}$. The strict inequality $v_{10}<v_{1 s}$ implies $\theta_{1 s}=1$. The second case has $v_{00}>v_{01}$. In this case, $\theta_{00}=1$, and so $q_{01}=0$. Recall that $q_{11}=0$ (since $\left.\theta_{11}=0\right)$. From (2.13), I can compute the payoff to a seller who has a related buyer in this case as

$$
J_{1}(\rho)=\frac{1}{1+r} \max _{p_{1}}\left\{\lambda \theta_{1 s} D_{s}\left(\rho_{+1}, p_{1}\right)+J_{0}\left(\rho_{+1}\right)\right\}, \text { s.t. }(2.4) .
$$

If $\theta_{1 s}<1$, the seller can increase the payoff by reducing $p_{1}$ slightly to induce $\theta_{1 s}=1$. This price reduction does not change other buyers' choices, because the seller only attracts his related buyer in this case. But this price reduction will increase the seller's value, which implies that $\theta_{1 s}<1$ cannot be equilibrium outcome.

To prove (ii) of Lemma 3.1, suppose $\theta_{00}=0$ (i.e., $\theta_{01}=1$ ), to the contrary. Since $q_{00}=0$ in this case, and since $q_{10}=0$ (as a result of $\theta_{10}=0$ ), then (2.10) yields $v_{00}=$ $U-p_{0}+V_{1}\left(\rho_{+1}\right)$. A seller without a related buyer can set $p_{0}=p_{1}-\varepsilon$, where $\varepsilon>0$ is sufficiently small. Doing so will yield $v_{00}>v_{1 s}>v_{01}$ and, hence, $\theta_{00}=1$ that contradicts the supposition $\theta_{01}=1$. To prove (iii) of Lemma 3.1, note that $\theta_{01}>0$ implies $v_{00} \leq v_{01}$. Since $v_{1 s}>v_{01}$, then $v_{1 s}>v_{00}=v_{10}$ in this case. For (iv) of Lemma 3.1, note that $v_{1 s} \geq v_{10}=v_{00}$, where the inequality follows from $\theta_{1 s}=1$. If $\theta_{01}=0$, the formula of $J_{1}$ in the above proof is valid. If $v_{1 s}>v_{00}$ in this case, a seller with a related buyer can raise $p_{1}$ slightly without disturbing the outcome $\theta_{1 s}=1$, thus increasing his payoff. Therefore, $v_{1 s}=v_{00}$ must hold if $\theta_{01}=0$. This completes the proof of Lemma 3.1.

Now turn to Lemma 3.2. Suppose, contrary to the lemma, that an equilibrium with partial mixing (and priority) exists. Then, the optimal pair $\left(p_{1}, q_{1}\right)$ for a related seller 
solves (3.7) subject to the following additional constraint:

$$
\left[1-(1-\lambda) e^{-q_{1}}\right] D_{s}\left(\rho_{+1}, p_{1}\right) \geq \lambda D_{s}\left(\rho_{+1}, \bar{p}\right)
$$

This constraint requires that for a type- 1 seller, the choice of attracting both types of buyers should indeed weakly dominate the choice of attracting only the related buyer. If (A.1) is binding, then the type- 1 seller can gain by deviating to $\bar{p}$ that attracts only the related buyer. Thus, for an equilibrium with partial mixing to exist, (A.1) cannot be binding. In this case, the first-order condition of the problem in (3.7) yields:

$$
V_{0}^{a}(\rho)-V_{0}\left(\rho_{+1}\right)=\frac{(1-\lambda)^{2}\left(1-e^{-q_{1}}\right)^{2} e^{-q_{1}} \Delta\left(\rho_{+1}\right)}{(1-\lambda)\left[1-e^{-q_{1}}\right]^{2}+\lambda\left[1-\left(1+q_{1}\right) e^{-q_{1}}\right]},
$$

where $\Delta$ is defined in (3.4). Moreover, (3.7) yields:

$$
(1+r) J_{1}(\rho)-J_{0}\left(\rho_{+1}\right)=\frac{\left[1-\left(1+q_{1}\right) e^{-q_{1}}\right]\left[1-(1-\lambda) e^{-q_{1}}\right]^{2} \Delta\left(\rho_{+1}\right)}{(1-\lambda)\left[1-e^{-q_{1}}\right]^{2}+\lambda\left[1-\left(1+q_{1}\right) e^{-q_{1}}\right]} .
$$

A type-0 seller's optimization problem is (3.1), which yields the optimality conditions (3.2) and (3.3). By equating the two expressions for $\left[V_{0}^{a}(\rho)-V_{0}\left(\rho_{+1}\right)\right]$ in (3.2) and (A.2), I get the following relation between $q_{0}$ and $q_{1}$ :

$$
q_{0}=h\left(q_{1}\right) \equiv q_{1}+\ln \left\{\frac{1}{1-\lambda}\left[1+\frac{\lambda}{1-\lambda} \frac{\left[1-\left(1+q_{1}\right) e^{-q_{1}}\right]}{\left(1-e^{-q_{1}}\right)^{2}}\right]\right\} .
$$

It can be verified that $h(q)$ is an increasing function for all $q>0$.

I prove that these conditions lead to the result $J_{0}(\rho)>J_{1}(\rho)$, which violates the equilibrium requirement that it be optimal for a type-1 seller to give priority to the related buyer. To start, I substitute $(1+r) J_{0}(\rho)$ from $(3.3)$ and $(1+r) J_{1}(\rho)$ from (A.3) to rewrite the relation $J_{0}(\rho)>J_{1}(\rho)$ as

$$
1-\left(1+q_{0}\right) e^{-q_{0}}>\frac{\left[1-\left(1+q_{1}\right) e^{-q_{1}}\right]\left[1-(1-\lambda) e^{-q_{1}}\right]^{2}}{(1-\lambda)\left[1-e^{-q_{1}}\right]^{2}+\lambda\left[1-\left(1+q_{1}\right) e^{-q_{1}}\right]} .
$$

Here I have used the fact that $\Delta\left(\rho_{+1}\right)>0$, where $\Delta$ is defined in (3.4). Substituting $q_{0}=h\left(q_{1}\right)$ from (A.4), I rewrite the above condition further as $f\left(a, q_{1}\right)<0$, where $a$ temporarily denotes $a=\frac{1}{1-\lambda}$ and $f$ temporarily denotes

$$
f(a, q)=\ln \left\{a\left[1+(a-1) \frac{1-(1+q) e^{-q}}{\left(1-e^{-q}\right)^{2}}\right]\right\}-(a-1) \frac{\left[q_{1}+1-\left(2 q_{1}+1\right) e^{-q_{1}}\right]}{\left(1-e^{-q_{1}}\right)^{2}} .
$$


Note that $a>1$. Also, $f(1, q)=0$ for all $q>0$. Compute:

$$
\frac{\partial f(a, q)}{\partial a}=\frac{1}{a}+\left[a-1+\frac{\left(1-e^{-q}\right)^{2}}{1-(1+q) e^{-q}}\right]^{-1}-\frac{\left[q_{1}+1-\left(2 q_{1}+1\right) e^{-q_{1}}\right]}{\left(1-e^{-q_{1}}\right)^{2}} .
$$

From this expression it is easy to verify that

$$
\frac{\partial f(1, q)}{\partial a}=1-\frac{q}{1-e^{-q}}<0 \text { for all } q>0
$$

It is also easy to verify that $\frac{\partial f(a, q)}{\partial a}$ is decreasing in $a$ for all $q>0$ and all $a>1$. Thus, for all $a>1$ and $q>0$, the following results hold:

$$
\frac{\partial f(a, q)}{\partial a}<\left.\frac{\partial f(a, q)}{\partial a}\right|_{a=1}<0, \quad f(a, q)<f(1, q)=0 .
$$

This establishes the result $J_{0}(\rho)>J_{1}(\rho)$ under partial mixing and, hence, proves that an equilibrium with partial mixing (and priority) does not exist. QED

\section{B. Proof of Proposition 3.3}

Let me first prove part (ii) of Proposition 3.3. The dynamics of $\rho$ are determined by (3.11), given the initial value of $\rho$. For each value of $\rho$ on the dynamic path, $q_{0}$ is given by (3.10). Because (3.10) and (3.11) depend only on $(\lambda, b)$, the steady state and the dynamics of $\left(\rho, q_{0}\right)$ depend only on $(\lambda, b)$. Let me solve the steady state of $\left(\rho, q_{0}\right)$, denoted $\left(\rho^{*}, q_{0}^{*}\right)$. In the steady state, $\rho_{+1}=\rho=\rho^{*}$, and so (3.11) and $H(\rho)=q_{0}$ yield:

$$
\rho^{*}=\rho 1\left(q_{0}^{*}\right) \equiv\left[1+\frac{1-\lambda}{1-e^{-q_{0}^{*}}}\right]^{-1} .
$$

Rewriting (3.10) as $\rho=b\left[1+\frac{1}{\lambda}\left(\frac{1}{\rho}-1\right) q_{0}\right]^{-1}$ and substituting $\rho^{*}=\rho 1\left(q_{0}^{*}\right)$, I get:

$$
\rho^{*}=\rho 2\left(q_{0}^{*}\right) \equiv b\left[1+\frac{1-\lambda}{\lambda} \frac{q_{0}^{*}}{1-e^{-q_{0}^{*}}}\right]^{-1} \text {. }
$$

The steady-state values, $\left(\rho^{*}, q_{0}^{*}\right)$, solve $\rho^{*}=\rho 1\left(q_{0}^{*}\right)=\rho_{2}\left(q_{0}^{*}\right)$. It is easy to verify that $\rho 1^{\prime}(q)>0, \rho 1(0)=0, \rho 1(\infty)=\frac{1}{2-\lambda}<1, \rho 2^{\prime}(q)<0, \rho 2(0)=b \lambda>0$, and $\rho 2(\infty)=0$. Thus, there exists a unique $q_{0}^{*} \in(0, \infty)$ that solves $\rho 1\left(q_{0}^{*}\right)=\rho 2\left(q_{0}^{*}\right)$. The implied solution for $\rho^{*}$ satisfies $\rho^{*} \in(0,1)$, because $\rho 1\left(q_{0}^{*}\right) \in(0,1)$. Also, $\rho^{*}<b \lambda$ because $\rho 2\left(q_{0}^{*}\right)<b \lambda$. 
Thus, $0<\rho^{*}<\min \{1, b \lambda\}$, as it is stated in part (ii) of the proposition. Also, it is straightforward to use (B.1) and (B.2) to verify that $\frac{d \rho^{*}}{d b}>0, \frac{d q_{0}^{*}}{d b}>0$, and $\frac{d \rho^{*}}{d \lambda}>0$.

Continuing the proof of part (ii), I show that the steady state is locally stable. This is equivalent to proving that the steady state of $\rho$ is locally stable, because $\rho$ is the only aggregate state variable. In turn, the steady state of $\rho$ is locally stable if and only if $\left|G^{\prime}\left(\rho^{*}\right)\right|<1$, where $G$ is defined in (3.11). Using (3.10) to compute $H^{\prime}(\rho)=\left(q_{0}-\lambda\right) /(1-\rho)$ first and then $G^{\prime}$, I have:

$$
G^{\prime}(\rho)=\left(1-\lambda+q_{0}\right) e^{-q_{0}}-(1-\lambda), \text { where } q_{0}=H(\rho) .
$$

Clearly, $G^{\prime}(\rho)>-(1-\lambda)>-1$. Also, $G^{\prime}(\rho)<q_{0} e^{-q_{0}}<1$. Thus, $\left|G^{\prime}(\rho)\right|<1$ for all $\rho$ such that $q_{0}=H(\rho)>0$. In particular, $\left|G^{\prime}\left(\rho^{*}\right)\right|<1$.

For part (i) of Proposition 3.3, let me first presume $\Delta\left(\rho_{+1}\right)>0$ (which will be verified in part (iii)) and find the conditions for $J_{1}(\rho) \geq J_{0}(\rho)$ and (3.9). Consider the condition $J_{1}(\rho) \geq J_{0}(\rho)$. Using (3.5) and $V_{0}^{a}$ in (3.2), I compute:

$$
\bar{p}=U+V_{1}\left(\rho_{+1}\right)-V_{0}\left(\rho_{+1}\right)-e^{-q_{0}} \Delta\left(\rho_{+1}\right) .
$$

Then, a type-1 seller's expected surplus and the value function are

$$
\begin{aligned}
& \lambda\left[\bar{p}-c+J_{1}\left(\rho_{+1}\right)-J_{0}\left(\rho_{+1}\right)\right]=\lambda\left(1-e^{-q_{0}}\right) \Delta\left(\rho_{+1}\right), \\
& (1+r) J_{1}(\rho)=J_{0}\left(\rho_{+1}\right)+\lambda\left(1-e^{-q_{0}}\right) \Delta\left(\rho_{+1}\right) .
\end{aligned}
$$

Comparing (B.5) with (3.3), I express the condition $J_{1}(\rho) \geq J_{0}(\rho)$ equivalently as $\frac{q_{0}}{e^{q_{0}}-1} \geq$ $1-\lambda$. Because $\frac{q}{e^{q}-1}$ is a decreasing function of $q$ for all $q>0$ and its value lies in $(0,1)$, this condition is equivalent to $q_{0} \leq q_{a}(\lambda)$ where $q_{a}$ is defined by the following equation:

$$
\frac{q_{a}}{e^{q_{a}}-1}=1-\lambda
$$

Note that $q_{a}(\lambda)$ is an increasing function of $\lambda$. Moreover, because $-\ln (1-\lambda)>\lambda$ for all $\lambda \in(0,1)$, it can be verified that $\frac{q}{e^{q}-1}>1-\lambda$ at $q=-\ln (1-\lambda)$, which implies $q_{a}(\lambda)>-\ln (1-\lambda)>\lambda$. 
Now consider the condition (3.9), still under the presumption $\Delta\left(\rho_{+1}\right)>0$. Because $\tilde{q}_{1}$ satisfies (A.2), the consistency between (A.2) and (3.2) requires $q_{0}=h\left(\tilde{q}_{1}\right)$, where $h$ is defined in (A.4). The price $\tilde{p}_{1}$ can be retrieved from (3.8). Thus,

$$
\tilde{q}_{1}=h^{-1}\left(q_{0}\right), \quad \tilde{p}_{1}=U+V_{1}\left(\rho_{+1}\right)-V_{0}\left(\rho_{+1}\right)-\frac{\tilde{q}_{1}\left[V_{0}^{a}-V_{0}\right]}{\left(1-e^{-\tilde{q}_{1}}\right)(1-\lambda)} .
$$

Substituting $\tilde{p}_{1}$ from (B.7), $\bar{p}$ from (B.3), and $q_{0}=h\left(\tilde{q}_{1}\right)$, I can write (3.9) equivalently as $f\left(\tilde{q}_{1}\right) \leq 0$, where $f$ temporarily denotes:

$$
f(q)=e^{2 q}-\left[2-2 \lambda+\lambda^{2}+(1+\lambda) q\right] e^{q}+(1-\lambda)(1-\lambda+q) .
$$

Note that $f(0)=0, f(\infty)=\infty$ and compute:

$$
f^{\prime}(q)=2 e^{2 q}-\left[3-\lambda+\lambda^{2}+(1+\lambda) q\right] e^{q}+1-\lambda .
$$

Note that $f^{\prime}(0)=-\lambda^{2}<0, f^{\prime}(\infty)=\infty$ and compute:

$$
f^{\prime \prime}(q)=e^{q}\left[4 e^{q}-4-\lambda^{2}\right] .
$$

Thus, $f^{\prime \prime}(q)>0$ if and only if $q>\ln \left(1+\frac{\lambda^{2}}{4}\right)$. With the properties of $f^{\prime}(0)$ and $f^{\prime}(\infty)$, this result implies that there exists $q_{4} \in\left(0, \ln \left(1+\frac{\lambda^{2}}{4}\right)\right)$ such that $f^{\prime}(q)>0$ if and only if $q>q_{4}$. In turn, with the properties of $f(0)$ and $f(\infty)$, this result implies that there exists $q_{5}(\lambda) \in\left(q_{4}, \infty\right)$ such that $f(q)>0$ if and only if $q>q_{5}(\lambda)$. That is, $f\left(\tilde{q}_{1}\right) \leq 0$ if and only if $\tilde{q}_{1} \leq q_{5}(\lambda)$. It can be verified that $h(q)$ defined in (A.4) is an increasing function. Because $q_{0}=h\left(\tilde{q}_{1}\right)$, then $\tilde{q}_{1} \leq q_{5}(\lambda)$ if and only if

$$
q_{0} \leq q_{b}(\lambda) \equiv h\left(q_{5}(\lambda)\right) \in(0, \infty)
$$

Therefore, the requirement $J_{1}(\rho) \geq J_{0}(\rho)$ and the requirement (3.9) are both satisfied if and only if $q_{0} \leq Q(\lambda)$, where $Q(\lambda)$ is defined as

$$
Q(\lambda)=\min \left\{q_{a}(\lambda), q_{b}(\lambda)\right\} \in(0, \infty) .
$$

Because $\rho 2(q)<\rho 1(q)$ if and only if $q>q_{0}^{*}$, the steady state of the equilibrium satisfies $q_{0}^{*} \leq Q(\lambda)$ if and only if $\rho 2(Q(\lambda)) \leq \rho 1(Q(\lambda))$, which can be rewritten as $b \leq B(\lambda)$ where

$$
B(\lambda) \equiv \frac{\lambda\left[1-e^{-Q(\lambda)}\right]+(1-\lambda) Q(\lambda)}{\lambda\left[2-\lambda-e^{-Q(\lambda)}\right]} .
$$


Together with part (i), this establishes that a steady state with complete separation exists if and only if $b \leq B(\lambda)$. Under this condition, the steady state is unique. It is clear from the definitions of $q_{a}(\lambda)$ and $q_{b}(\lambda)$ that they depend only on $\lambda$ and not on other parameters such as $c$ and $U$. Thus, $Q(\lambda)$ and $B(\lambda)$ depend only on $\lambda$.

For part (iii) of Proposition 3.3, recall that $\bar{p}$ in (3.5) is derived from the relation $v_{1 s}(\rho, \bar{p})=V_{0}^{a}(\rho)$. Hence, (2.7) implies $V_{1}(\rho)=V_{0}(\rho)$. Substituting $V_{0}^{a}$ from the first condition in (3.2) into (2.7) for $i=0$ yields the expression for $V$ in (3.14). Combining the two conditions in (3.2) to eliminate $V_{0}^{a}$ yields the expression for $p_{0}$ in (3.12), and substituting the result $V_{1}=V_{0}$ into (B.3) yields the expression for $\bar{p}$ in (3.13). Because $\frac{q}{1-e^{-q}}>1$ for all $q>0$ and $\Delta>0$, it is clear that $\bar{p}>p_{0}$. Let me delay the proof of $\bar{p}>c$.

To derive the dynamic equation for $\Delta$ in (3.15) and verify $\Delta(\rho)>0$ for $\rho$ near the steady-state value $\rho^{*}$, I subtract (3.3) from (B.5) to get:

$$
J_{1}(\rho)-J_{0}(\rho)=\frac{1}{1+r}\left[\lambda\left(1-e^{-q_{0}}\right)-1+\left(1+q_{0}\right) e^{-q_{0}}\right] \Delta\left(\rho_{+1}\right) .
$$

The definition of $\Delta(\rho)$ in (3.4) and the result $V_{1}=V_{0}$ then imply the dynamic equation for $\Delta$ in (3.15). Setting $\Delta(\rho)=\Delta\left(\rho_{+1}\right)=\Delta^{*}$ and $q_{0}=q_{0}^{*}$ in (3.15), I obtain:

$$
\Delta^{*}=\frac{(1+r)(U-c)}{1+r-\lambda\left(1-e^{-q_{0}^{*}}\right)+1-\left(1+q_{0}^{*}\right) e^{-q_{0}^{*}}} .
$$

Because $r>0,1>\lambda\left(1-e^{-q_{0}^{*}}\right), 1>\left(1+q_{0}^{*}\right) e^{-q_{0}^{*}}$ and $U>c$, then $\Delta^{*}>0$. If $\rho$ is close to $\rho^{*}$, then $q_{0}=H(\rho)$ is close to $q_{0}^{*}$, in which case $\Delta(\rho)$ is close to $\Delta^{*}$ and, hence, $\Delta(\rho)>0$.

With (B.12) and (3.13), I can deduce that $\bar{p}^{*}>c$ if and only if

$$
(1+r-\lambda)\left(1-e^{-q_{0}^{*}}\right)+1-\left(1+q_{0}^{*}\right) e^{-q_{0}^{*}}>0 .
$$

Note that the left-hand is an increasing function of $q_{0}^{*}$, and its value is 0 if $q_{0}^{*}=0$. Because $q_{0}^{*}>0$, then the left-hand side is strictly positive, indeed. Thus, if $\rho$ is close to $\rho^{*}$, then $\bar{p}>c$. This completes the proof of Proposition 3.3. QED 


\section{References}

[1] Acemoglu, D. and R. Shimer, 1999, "Efficient Unemployment Insurance," Journal of Political Economy 107, 893-928.

[2] Albrecht, J., Gautier, P.A., and S. Vroman, 2006, "Equilibrium Directed Search with Multiple Applications," Review of Economic Studies 73, 869-891.

[3] Albrecht, J., Postel-Vinay, F. and S. Vroman, 2011, "An Equilibrium Search Model of Sales," manuscript, Georgetown University.

[4] Bagwell, K., 1987, "Introductory Price as a Signal of Cost in a Model of Repeat Business," Review of Economic Studies 54, 365-384.

[5] Blattberg, R.C. and S.K. Sen, 1974, "Market Segmentation Using Models of Multidimensional Purchasing Behavior," Journal of Marketing 38, 17-28.

[6] Burdett, K., and K. Judd, 1983, "Equilibrium Price Dispersion," Econometrica 51, 955-970.

[7] Burdett, K., Shi, S. and R. Wright, 2001, "Pricing and Matching with Frictions," Journal of Political Economy 109, 1060-1085.

[8] Chevalier, J.A., Kashyap, A.K. and P.E. Rossi, 2003, "Why Don't Prices Rise during Periods of Peak Demand? Evidence from Scanner Data," American Economic Review 93, 15-37.

[9] Dutta, S. Bergen, M., and D. Levy, 2002, "Price Flexibility in Channels of Distribution: Evidence from Scanner Data," Journal of Economic Dynamics and Control 26, 1845-1900.

[10] Galenianos, M. and P. Kircher, 2009, "Directed Search with Multiple Job Applications," Journal of Economic Theory 144, 445-471.

[11] Gonzalez, F.M. and S. Shi, 2010, "An Equilibrium Theory of Learning, Search and Wages," Econometrica 78, 509-537.

[12] Gourio, F. and L. Rudanko, 2011, "Customer Capital," manuscript, Boston University.

[13] Guerrieri, V., Shimer, R. and R. Wright, 2010, "Adverse Selection in Competitive Search Equilibrium," Econometrica 78, 1823-1862. 
[14] Julien, B., Kennes, J. and I. King, 2000, "Bidding for Labor," Review of Economic Dynamics 3, 619-649.

[15] Kircher, P., 2009, "Efficiency of Simultaneous Search," Journal of Political Economy $117,861-913$.

[16] Klenow, P. and O. Kryvtsov, 2008, "State-Dependent or Time-Dependent Pricing: Does It Matter for Recent US Inflation?" Quarterly Journal of Economics 123, 863904.

[17] Lazear, E.P., 1986, "Retail Pricing and Clearance Sales," American Economic Review $76,14-32$.

[18] Menzio, G. and S. Shi, 2011, "Efficient Search on the Job and the Business Cycle," Journal of Political Economy 119, 468-510.

[19] Milgrom, P. and J. Roberts, 1986, "Price and Advertising Signals of Product Quality," Journal of Political Economy 94, 796-821.

[20] Moen, E.R., 1997, "Competitive Search Equilibrium," Journal of Political Economy $105,385-411$.

[21] Montgomery, J.D., 1991, "Equilibrium Wage Dispersion and Interindustry Wage Differentials," Quarterly Journal of Economics 106, 163-179.

[22] Nakamura, E. and J. Steinsson, 2008, "Five Facts about Prices: A Reevaluation of Menu Cost Models," Quarterly Journal of Economics 123, 1415-1464.

[23] Pesendorfer, M., 2002, "Retail Sales: A Study of Pricing Behavior in Supermarkets," Journal of Business 75, 33-66.

[24] Peters, M., 1984, "Bertrand equilibrium with Capacity Constraints and Restricted Mobility," Econometrica 52, 1117-1127.

[25] Peters, M., 1991, "Ex Ante Price Offers in Matching Games: Non-Steady State," Econometrica 59, 1425-1454.

[26] Salop, S. and J. Stiglitz, 1982, "The Theory of Sales: A Simple Model of Equilibrium Price Dispersion with Identical Agents," American Economic Review 72, 1121-1130.

[27] Shi, S., 2002, "A Directed Search Model of Inequality with Heterogeneous Skills and Skill-Biased Technology," Review of Economic Studies 69, 467-491. 
[28] Shi, S., 2006, "Wage Differentials, Discrimination and Efficiency," European Economic Review 50, 849-875.

[29] Shi, S., 2009, "Directed Search for Equilibrium Wage-Tenure Contracts," Econometrica $77,561-584$.

[30] Shi, S., 2011, "Customer Relationship and Sales," Working paper 429, University of Toronto.

[31] Shilony, Y., 1977, "Mixed Pricing in Oligopoly," Journal of Economic Theory 14, 373-388.

[32] Shimer, R., 2005, "The Assignment of Workers to Jobs in an Economy with Coordination Frictions," Journal of Political Economy 113, 996-1025.

[33] Sobel, J., 1984, "The Timing of Sales," Review of Economic Studies 51, 353-368.

[34] Varian, H., 1980, "A Model of Sales," American Economic Review 70, 651-659. 